\title{
АРТИКОВ
}

Акрам Музафарович

\section{МЮОННЫЙ КОМПЛЕКС И ПРЕКОНВЕРТОР ЭЛЕКТРОМАГНИТНОГО КАЛОРИМЕТРА УСТАНОВКИ СDF II В ЭКСПЕРИМЕНТАХ ПО ФИЗИКЕ ТЯЖЁЛЫХ КВАРКОВ НА ТЕВАТРОНЕ}

01.04.16 - физика атомного ядра и элементарных частиц

Автореферат диссертации на соискание учёной степени доктора физико-математических наук 
Работа выполнена в Самаркандском государственном университете и в Объединенном институте ядерных исследований, г. Дубна (Россия)

Официальные оппоненты: доктор физико-математических наук, академик АН РУз Юлдашбаев

\section{Таймас Саттыевич}

доктор физико-математических наук, профессор Батусов Юрий Александрович

доктор технических наук, старший научный сотрудник Коблик

\section{Юрий Никифорович} $\begin{array}{ll}\text { Ведущая организация: } & \text { Физический институт им. Лебедева РАН, г. } \\ \text { Москва. }\end{array}$

Защита состоится « 2009 г. В часов на заседании объединенного специализированного совета Д015.15.02 по защите диссертаций на соискание ученой степени доктора наук при Институте ядерной физики АН РУз по адресу: 100214, г. Ташкент, Мирзо-Улугбекский район, пос. Улугбек, ИЯФ АН РУз; тел.: (8-10-998-71) 289 - 31 - 41; факс: (810-998-71) 150 - 30 - 80

С диссертацией можно ознакомиться в библиотеке ИЯФ АН РУз и Фундаментальной библиотеке АН РУз.

Автореферат разослан « " 2009 г.

Ученый секретарь объединенного специализированного совета доктор физ.-мат. наук, профессор 


\section{ОБЩАЯ ХАРАКТЕРИСТИКА РАБОТЫ}

Актуальность работы.

Исследование столь важных для современной физики высоких энергий направлений, как высокоточные измерения масс $W$-бозона и $t$-кварка, позволяющие ограничить допустимую область масс существования Хиггс бозона, детальное изучение распадов $B$-мезонов, $B$-барионов и других задач стало возможным после модернизации в 1996-2000 гг. установки CDF. Увеличение светимости ТЭВАТРОНА и аксептанса установки CDF II способствовали накоплению интегральной светимости, в несколько раз превышающей светимость, набранную в течение первого сеанса (1992-1995). Таким образом, осуществлен переход к статистически обеспеченным экспериментам и, в частности, начато новое направление в физике высоких энергий - физика $t$-кварков.

Сцинтилляционные детекторы используются в физическом эксперименте уже несколько десятилетий благодаря систематическим исследованиям, нацеленным на улучшение долговременной эффективности, быстродействия, способов съема света со сцинтиллятора, уменьшения стоимости единицы чувствительной площади детектора и других. В современных спектрометрических комплексах для экспериментов по физике высоких энергий сцинтилляционные и газовые координатные детекторы часто составляют единый комплекс, где быстродействующий сцинтилляционный детектор используется для однозначного выбора искомого события среди многих других, зарегистрированных трековыми детекторами. Примерами такого комплекса являются сцинтилляционные детекторы и дрейфовые камеры мюонного триггера CDF II, а также сцинтилляционный преконвертор и дрейфовая камера, составляющие единую систему вместе с электромагнитным калориметром и повышающие точность определения параметров ливня.

Диссертация включает результаты завершенных исследований предложенных автором в области разработки и испытания новых сцинтилляционных детекторов, а также результаты реализации новых методов их использования в физике высоких энергий $[1-4,11,20,21]$. Применение в эксперименте систем, созданных на базе наших новых разработок, обеспечило достижение важных новых результатов принципиального научного значения: высокоточных измерений масс $t$-кварка [5-7] и $W$-бозона [16], параметров осцилляции $B_{s}^{0}-\bar{B}_{s}^{0}$ мезонов [8, 9], времен жизни и масс $b / c$ адронов [12], а также ряда существенных проверок Стандартной Модели (СМ) [10, 13, 14].

Степень изученности проблемы. В течение первого сеанса (Run I) в 1992-1995 гг. CDF набрал статистику $110 n \sigma^{-1}$ при энергии сталкивающихся протонов и антипротонов в системе центра масс $\sqrt{s}=1.8$ Тэ $B$ и выполнил первые измерения свойств $t$-кварка. Для прецизионного измерения фундаментальной константы - массы $t$-кварка - крайне важной для 
определения области масс существования Хиггс бозона, необходимо значительно увеличить статистику. С этой целью в 1996-2000 гг. были модернизированы: а) Тэватрон, для увеличения светимости и энергии; б) установка CDF, для увеличения аксептанса и оснащения быстродействующими детекторными системами адекватными высокой светимости Тэватрона.

Крупногабаритные сцинтилляционные счетчики со съемом света переизлучающими оптическими волокнами в качестве детекторов мюонного триггера ранее в экспериментах на ускорителях не применялись. Их свойства не были изучены в достаточной степени. К примеру, полностью отсутствовала информация о технической длине ослабления и естественном старении детекторов подобного типа.

\section{Связь диссертационной работы с тематическими планами НИР:}

В диссертации обобщены результаты исследований, выполненных автором в 1998-2007 гг. во время работы в ОИЯИ и ФНАЛ в рамках ПТП ОИЯИ (тема 02-0-1022-97/08) и в рамках протоколов о сотрудничестве СамГУ - ОИЯИ (3118-2-98/01, 3422-2-02/04, 3666-2-05/07).

\section{Цель работы:}

Модернизация мюонного комплекса и преконвертора электромагнитного калориметра установки CDF II с целью выполнения высокоприоритетной программы экспериментов ОИЯИ-ФНАЛ по физике тяжелых кварков на Тэватроне, включающей прецизионные измерения масс $t$-кварка и $W$-бозона, детальное исследование распадов B-мезонов и др.

\section{Для достижения этой цели поставлены и решены задачи:}

- Разработка, создание и исследование свойств сцинтилляционных детекторов нового поколения [1-4] и методик их применения в экспериментах на установке CDF II.

- Создание системы сцинтилляционных детекторов мюонного триггера установки CDF II, включающего более 1140 сцинтилляционных счётчиков разного типа и размера [17]; создание аппаратно-программного комплекса для их оперативного контроля и мониторинга [2].

- Создание нового, сцинтилляционного, преконвертора электромагнитного калориметра с увеличенными на порядок быстродействием и сегментацией по псевдобыстроте для продолжения набора статистики при возросшей светимости Тэватрона [20,21].

- Проведение экспериментов с целью высокоточного измерения масс $t$ кварка и $W$-бозона, проверки CM и поиска явлений за ее пределами.

- Исследование естественного старения сцинтилляционных счётчиков мюонной системы установки CDF II и прогнозирование их долговременной эффективности $[15,19]$.

- Исследование и обоснование использования в условиях повышенной светимости Тэватрона нового мюонного триггера L1 в области $1.0 \leq|\eta| \leq 1.25$ [18]. 
Объекты и предмет исследования: объектами исследования являются процессы с c,b,t-кварками, мюонная система и триггер, преконвертор электромагнитного калориметра, пластические сцинтилляционные детекторы установки CDF II. Топологии «лептон + струи» и «дилептон» распада $t$ кварка, формулы мюонных триггеров для отбора событий при измерении массы $W$-бозона и других исследовавшихся процессов, свойства сцинтилляционных детекторов (эффективность, объемная и техническая длины ослабления, время высвечивания, светосбор и т.д.), способы съема света со сцинтиллятора и мн.др. являются предметами исследования.

Методы исследования: метод абсолютной калибровки спектрометрического канала, (DLM - dynamical likelihood method) метод наибольшего правдоподобия, метод «шаблонов», однофотонный метод Боллингера и Томаса, метод определения коэффициента старения, метод определения объемной длины ослабления $\left(\mathrm{BAL}^{1}\right)$ и технической длины ослабления $\left(\mathrm{TAL}^{2}\right)$.

\section{Основные положения, выносимые на защиту:}

1. Методы и результаты исследования параметров сцинтилляционных детекторов нового поколения с оптоволоконным съемом света.

2. Результаты завершённого комплекса разработок и исследований, выполненных с целью создания, внедрения и применения системы сцинтилляционных детекторов в мюонном комплексе и новом преконверторе CDF II в программе исследований ОИЯИ - ФНАЛ на Тэватроне в экспериментах по высокоточному измерению масс $t$-кварка и $\mathrm{W}$-бозона, измерению параметров осцилляции $B_{s}^{0}-\bar{B}_{s}^{0}$ мезонов и др.

3. Методику и результаты исследования долговременной эффективности мюонных сцинтилляционных счётчиков установки CDF II.

4. Результаты исследования нового мюонного триггера 1-го уровня в области $1.0<|\eta|<1.25$ в условиях повышенной светимости Тэватрона.

\section{Научная новизна:}

- Созданные нами детекторы мюонного комплекса CDF и преконвертора электромагнитного калориметра обеспечили получение важных новых научных результатов по ряду фундаментальных проблем современной физики высоких энергий. В частности, среди результатов подобного класса, одни из наиболее точных, на время получения, измерений массы топ-кварка $M_{t o p}=173,5_{-3,6}^{+3,7}$ (stat.) $\Gamma \ni B / c^{2}[5,6]$ и $M_{t o p}=170.1 \Gamma \ni B / c^{2} \pm 6.0($ stat.) \pm 4.1(syst.) [7] в т.н. модах “лептон+струи” и “дилептон” соответственно, наиболее точное измерение массы $W$-бозона $M_{W}=80413 \pm 48$ (stat.) $M э B / c^{2}$ [16] и др. [8-9, 12-14].

- В экспериментах на коллайдере впервые реализован для сцинтилляционных счетчиков большого размера метод съема света с помощью ленты из переизлучающего оптического волокна. Наши

\footnotetext{
${ }^{1}$ Bulk Attenuation Length - длина, на которой световой сигнал уменьшается в $\boldsymbol{e}$-раз по закону Бугера-Ламберта.

2 Техническая длина ослабления сцинтилляционного детектора определяется как длина, на которой световой сигнал уменьшается в $е$ раз.
} 
исследования показали: по целому ряду параметров детектор нового поколения превосходит классические сцинтилляционные счетчики со световодом типа “рыбий хвост”[3, 4, 11].

- Для исследования свойств детекторов подобного типа впервые предложен и отработан метод измерения собственного излучения сцинтиллятора для определения объемной длины ослабления (BAL) и получены новые результаты: впервые определено время нарастания ( 2 нс) импульса света в системе «UPS 923A + WLS оптоволокно»; впервые сделан вывод о различиях в структуре полимерных основ, являющихся причиной двукратного превосходства полистирольного сцинтиллятора UPS 923A по времени старения в сравнении с поливинилтолуольным сцинтиллятором NE 114.

- Создан новый мюонный триггер установки CDF путём включения в его состав системы крупногабаритных сцинтилляционных счётчиков с оптоволоконным съемом света. Ранее подобная методика в практике экспериментов по физике высоких энергий применялась только в калориметрии.

- Проведен цикл исследований старения сцинтилляционных счётчиков с разной полимерной основой и разными способами съёма света в радиационных условиях. Для счетчиков с оптоволоконным съёмом света впервые: определён вклад спектросмещающих волокон (20\%) в старение детектора; найдено, что техническая длина ослабления (TAL) света слабо зависит от времени $[15,19]$.

\section{Научная и практическая значимость результатов исследования:}

- Оригинальный способ съема света с помощью оптоволоконной ленты, реализованный в наших детекторах, увеличил время их эффективной эксплуатации [15, 19], тем самым обеспечив многолетний набор статистики с целью определения массы $t$-кварка и $W$-бозона с высокой точностью, поиск новых суперсимметричных частиц и Хиггс бозона, детальное изучение распадов $B$-мезонов и др.

- Существенно модернизирована система сцинтилляционных счётчиков мюонного триггера установки CDF II [1, 3, 14, 20]: на 60\% увеличен её аксептанс. Это достижение обусловлено созданием нами и включением в состав спектрометрического комплекса CDF II более 650 крупномасштабных сцинтилляционных счётчиков с общей площадью более $300 \mathrm{M}^{2}$, в том числе 608 счётчиков с оптоволоконным съёмом света; обеспечением системой управления и контроля более чем 1140 сцинтилляционных счетчиков установки CDF II.

- Предложенная новая методика измерения объемной длины ослабления BAL сцинтиллятором собственного излучения позволила объективно сравнивать качество сцинтилляторов разных производителей.

- Для выполнения исследовательской программы CDF II при возросшей светимости Тэватрона (до $2 \times 10^{32}$ c. $^{-2} c^{-1}$ и выше), в которой требуется идентификация электронов и фотонов, создан новый 2600-канальный 
годоскопический сцинтилляционный преконвертор с общей площадью более $40 \mathrm{M}^{2}$ с увеличенными на порядок быстродействием и сегментацией по псевдобыстроте в сравнении с ранее существовавшим детектором [20, 21].

- Получены ранее отсутствовавшие сведения по старению сцинтилляционных счётчиков установки CDF II: статистически достоверным способом установлено, что сцинтилляционные счётчики на основе поливинилтолуола стареют в 2 раза быстрее, чем счетчики из полистирола аналогичной геометрии. Коллаборации предложена мотивированная программа замены теряющих эффективность поливинилтолуольных счетчиков, использующихся на установке CDF c 1992 г. $[15,19]$.

- Предложен и экспериментально апробирован новый мюонный триггер 1го уровня в области $1.0<|\eta|<1.25$, необходимость в котором возникла в связи с ростом светимости Тэватрона. Этим достигается существенное (более $10 \%$ ) увеличение количества отбираемых событий с мюонами в качестве сигнатурной (триггерной) частицы [18].

Реализация результатов. Измеренные нами с высокой точностью масса t-кварка (включенная во всемирно признанную таблицу констант PDG) и масса W-бозона входят в объединенные данные по Тэватрону, которые используются группой физиков из DESY (Германия) для сужения области масс существования Хиггс бозона с использованием метода “Global FITTER”.

Предложенный оптоволоконный метод съема света с крупногабаритных сцинтилляционных детекторов применен нами для более 600 счетчиков мюонного триггера установки CDF II и для детекторов т.н. "MinBias" триггера установки АТЛАС.

Достоверность и обоснованность полученных результатов проведенных на установке CDF II многолетних исследований с применением в эксперименте авторских разработок детекторов и аппаратно-программных средств опирается, прежде всего, на получение сопоставимых физических результатов на другой установке - спектрометре D0 в Фермилаб; они обеспечены использованием комплекса современных методов и средств для выполнения экспериментов, хорошей воспроизводимостью экспериментальных результатов, анализом ошибок, непротиворечивостью полученных результатов с общефизическими представлениями и литературными данными.

Апробация работы. Основные результаты работы докладывались на научно-методических семинарах Лаборатории Ядерных Проблем Объединенного Института Ядерных Исследований, Ядерно-Физической Лаборатории Самаркандского Государственного Университета, совещаниях мюонной группы $\mathrm{CDF}$, международном симпозиуме по ядерным исследованиям и конференции по медицинским приложениям в Риме (2004г.). Присуждена первая премия ОИЯИ в 2006 г. за цикл работ по исследованию свойств сцинтилляционных детекторов мюонного триггера 
установки CDF II и вторая премия ЭЧАЯ по итогам конкурса публикаций в журнале "Письма в ЭЧАЯ" за 2005 год.

Опубликованность результатов: Основные результаты диссертации опубликованы в 21 научных работах, в престижных периодических научных изданиях - “Физика Элементарных Частиц и Атомного Ядра" (ЭЧАЯ), "Письма в ЭЧАЯ", в журналах Nuclear Instruments \& Methods, Physical Review D, Physical Review Letters.

Личный вклад. Соискателем сформулированы и обоснованы цель и задачи исследования. Все эксперименты, включенные в работу, выполнены лично соискателем либо при его непосредственном участии. В коллективных работах вклад соискателя является определяющим. Научные обобщения и объяснение результатов, представленных в настоящей работе, выполнены лично автором данной диссертации.

Структура и объем диссертации. Диссертация состоит из введения, четырёх глав и заключения, в котором приводятся основные результаты. Содержание работы изложено на 141 страницах текста и представлено на 78 рисунках и в 8 таблицах, список цитируемой литературы содержит 74 наименования.

\section{СОДЕРЖАНИЕ РАБОТЫ}

Во введении показана важность и актуальность работы, сформулированы её цели, перечислены выносимые на защиту результаты, подчёркнуты их новизна и практическая ценность.

В первой главе приведено общее описание ускорительного комплекса Тэватрон и установки CDF II, в создании ряда ключевых узлов которой автор принимал непосредственное участие. Дана программа основных физических исследований на этой установке.

Установка CDF II является детектором общего назначения и спроектирована для изучения протон-антипротонных столкновений на ускорителе Тэватрон в Фермилаб.

Повышение полной энергии в системе центра масс сталкивающихся частиц с 1.8 Тэ $B$ до 1.96 Тэ $B$, светимости с $2.5 \times 10^{31} \mathrm{~cm}^{-2} \mathrm{c}^{-1}$ до $3 \times 10^{32} \mathrm{~cm}^{-2} \mathrm{c}^{-1}$ (в наборных сеансах Run I и Run II соответственно), а также усовершенствование детекторов и увеличение аксептанса установки CDF позволили резко увеличить набираемую статистику. В исследовательской программе на установке CDF II можно выделить следующие направления, относящиеся к числу особо значимых проблем современной физики высоких энергий:

- изучение свойств $t$-кварка, измерение массы $t$-кварка $\mathrm{c}$ высокой точностью;

- измерение массы $W$-бозона с высокой точностью;

- поиск частиц Хиггса и т.д. 
Установка CDF II (рис. 1) имеет высокоточную систему регистрации заряженных частиц, калориметрическую систему высокой гранулярности и систему детектирования и идентификации мюонов.

Непосредственно вокруг вакуумной камеры, где происходят столкновения протон-антипротонных пучков, размещён кремниевый вершинный детектор, позволяющий весьма точно реконструировать треки с целью поиска в триггерном режиме вторичных вершин от распада короткоживущих частиц с тяжёлыми кварками.

За кремниевым вершинным детектором расположена центральная газовая трековая система, которая позволяет восстанавливать траектории регистрируемых частиц. Она вместе с кремниевыми детекторами образует единую трековую систему.

Единая трековая система установлена внутри сверхпроводящего соленоидального магнита размерами $1.5 \mathcal{M}$ по радиусу и $4.8 \mathcal{M}$ длиной, который создаёт поле величиной 1.4 Тесла (максимальная величина 1.5 Тесла) параллельно пучку частиц в полезном объёме радиусом 1.4 м и длиной $3.5 \mathrm{M}$.

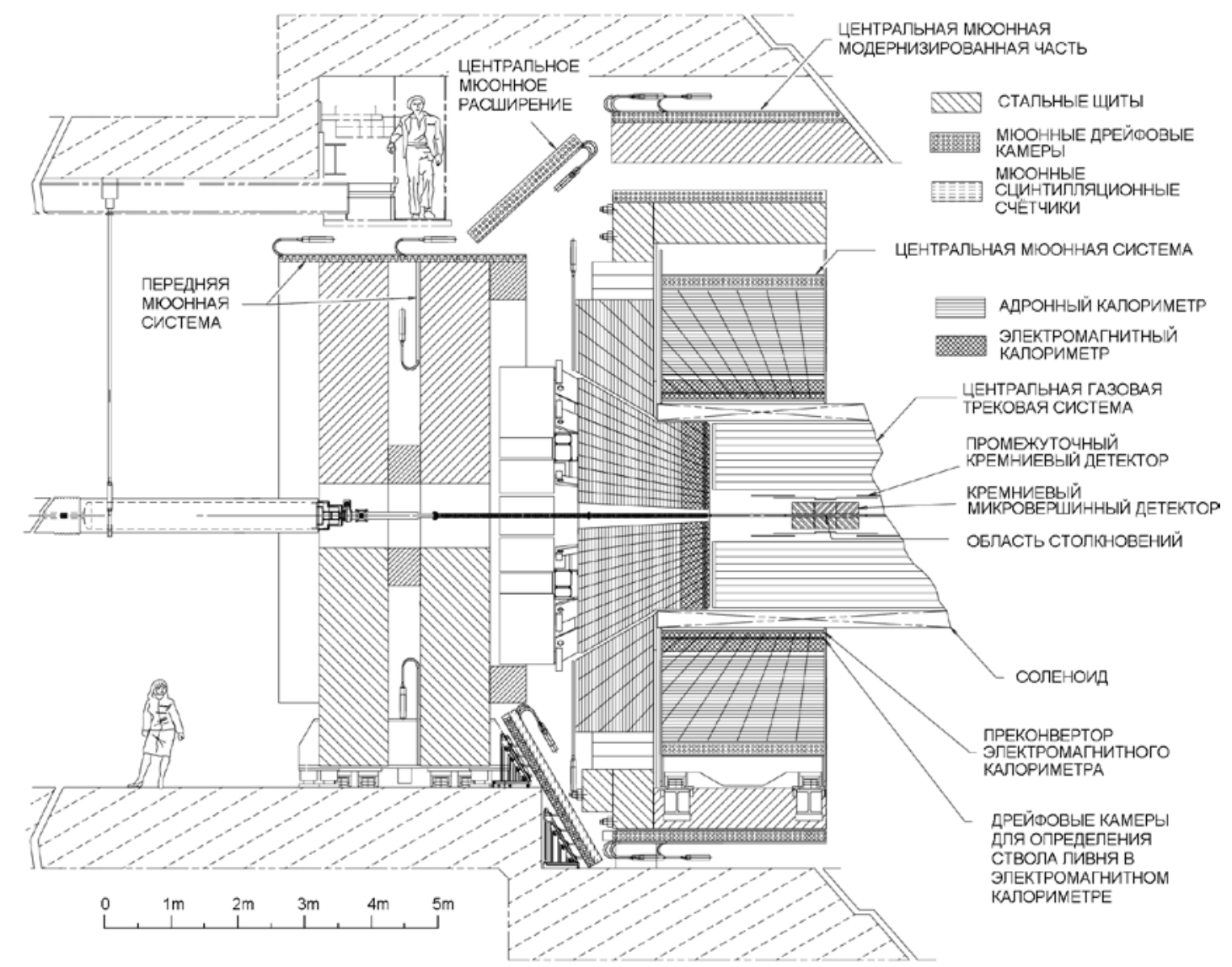

Рис. 1. Установка CDF в разрезе.

За соленоидом расположена калориметрическая система. С её помощью определяют энергию и координаты электронов, фотонов, адронов, а также струй. Калориметрическая система состоит из отдельных электромагнитных и адронных калориметров. 
Мюонная система является принципиально важной частью установки CDF II и состоит из сцинтилляционных счётчиков и дрейфовых камер.

Система сбора данных установки CDF II способна принимать входящую информацию от детекторов с частотой до $1.7 \mathrm{MГц.} \mathrm{Трёхуровневая} \mathrm{система}$ триггеров позволяет снизить конечную частоту записи на постоянный носитель до 50 Гц.

Специально разработанное программное обеспечение осуществляет мониторирование и контроль детекторов установки в режиме реального времени при наборе данных на Тэватроне.

Во второй главе описывается система мюонных сцинтилляционных счётчиков установки CDF, а также организация сбора данных, управление параметрами, оперативный контроль и мониторирование сцинтилляционных счётчиков. Приводится ряд существенных физических результатов, достигнутых с участием мюонного триггера.
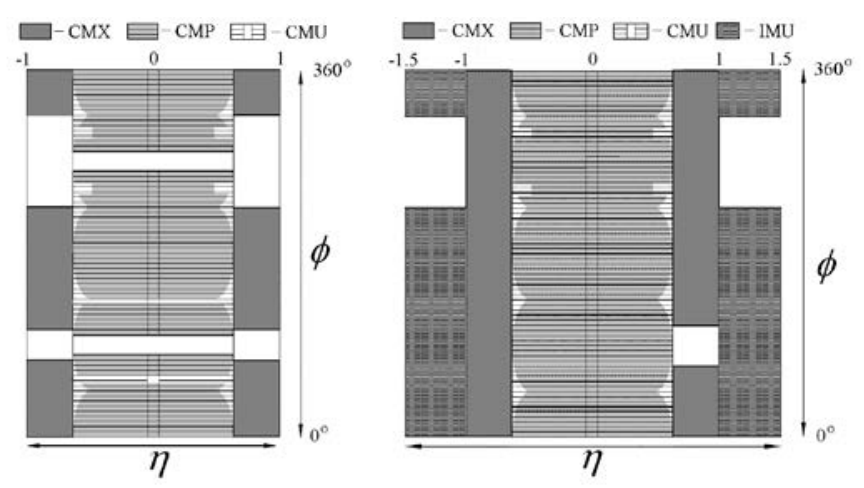

Рис. 2. Аксептанс мюонной системы CDF в наборных сеансах Run I - слева и в Run II - справа.

По плану развития установки CDF между наборными сеансами Run I и Run II в мюонную систему добавлено значительное количество (более 700) новых счётчиков и дрейфовых камер. В результате аксептанс мюонной системы CDF был увеличен радикально, на $60 \%$, в сравнении с сеансом Run I (рис. 2).

Мюонные сцинтиляционные счетчики покрывают область псевдобыстрот $0<|\eta|<1.5$ и сгруппированы в следующие основные подсистемы (рис. 3):

- Модернизированный Центральный Мюонный Сцинтилляционный Детектор - счётчики $\operatorname{CSP}^{3}$ в интервале $0 \leq|\eta| \leq 0.6$;

- Расширение Центрального Мюонного Сцинтилляционного Детектора счётчики $\operatorname{CSX}^{4}$ и счётчики CSX «miniskirt» (MSK) в интервале $0.6 \leq|\eta| \leq 1.0$;

${ }^{3}$ CSP - Central Scintillator uPgrade.

${ }^{4}$ CSX - Central Scintillator eXtension. 
- Сцинтилляционные счётчики Передней Мюонной Системы IMU ${ }^{5}$ : счетчики BSU, облегающие тороиды, и счетчики TSU внутри тороидов в интервале $1.0 \leq|\eta| \leq 1.5$.

Общее количество мюонных сцинтилляционных счётчиков на CDF II превосходит 1140 штук. Используются счетчики разных типов со съёмом света: с помощью плексигласового световода (т. н. «старые» счётчики), с помощью спектросмещающих волокон (т. н. счётчики нового поколения) и совмещающие оба указанных способа (т. н. «модернизированные»). Они разделяются на два вида по типу используемых фотоумножителей (ФЭУ): счётчики с традиционным съёмом света и большим ФЭУ; счётчики с оптоволоконным съёмом света и фотосенсорами на основе миниатюрных ФЭУ.

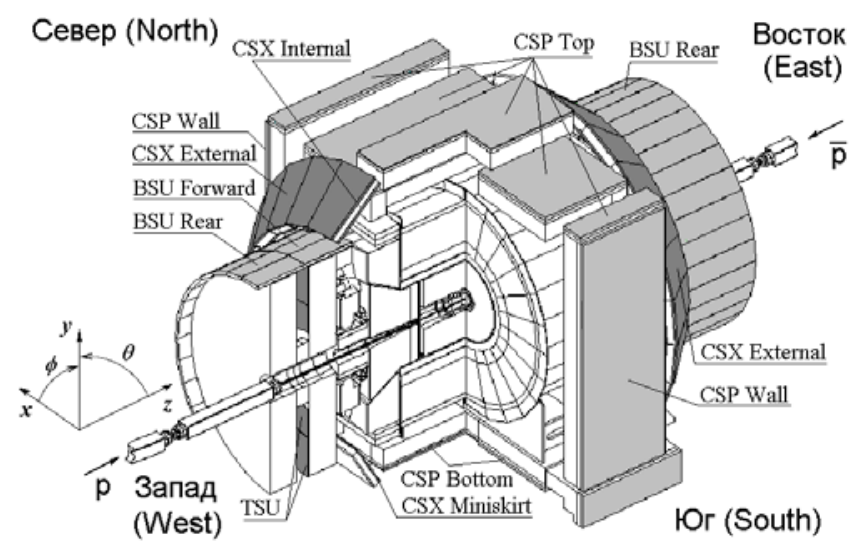

Рис. 3. Система мюонных сцинтилляционных счётчиков установки CDF II.

Мюонный комплекс (МК) играет принципиальную роль на установке CDF II. Сцинтилляционные счётчики и дрейфовые камеры МК используются при формировании триггеров (Таблица 1) и в "off-line" анализе при отборе и исследовании широкого круга протон-антипротонных взаимодействий с участием $c, b, t$-кварков, где, по условиям эксперимента, ожидается рождение мюона в цепочках распада вторичных частиц [17].

Например, в исследовании процессов с $t$-кварками триггер IMU второго уровня L2 формируется из триггера первого уровня L1 с дополнительным требованием наличия в адронном калориметре струй с энергией $E_{T}>15$ Гэ $B$ в области $|\eta|<1.1$ (Таблица 1, строка 1 и 2, условие CJET15). А триггер для отбора мюонов с большим поперечным импульсом в области $0.6 \leq|\eta| \leq 1.0$ и требованием наличия струи в центральной области CDF (Таблица 1, строка 4, РТ15 и JET10), используется в исследовании многих процессов, как указано в крайней правой колонке 4-строки.

На события, отобранные “on-line” триггерами при дальнейшей обработке могут налагаться дополнительные требования. К примеру, при измерении массы $t$-кварка в моде “лептон + струи” события отбирались для анализа с требованием электронного или мюонного кандидата с поперечным

${ }^{5}$ IMU - Intermediate Muon Upgrade, BSU - Barrel Scintillator Upgrade, TSU - Toroid Scintillator Upgrade. 
импульсом $p_{T}>20$ Гэ $B$ и $|\eta|<1$ и кандидата на нейтрино с недостающей энергией превышающей 20 Гэ $B$. Для подавления фона требовалось также:

a) 4 струи с поперечной энергией $E_{T}>21$ Гэ $B$

Таблица 1.

Примеры “on-line" триггеров первого и второго уровня из общего набора использовавшихся триггеров (левая колонка). Цифры в правой колонке соответствуют перечисленным в списке литературы экспериментам, где сцинтилляционные счетчики участвовали в on-line или off-line отборе событий.

\begin{tabular}{|c|c|c|c|}
\hline $\mathrm{N}$ & Полная формула триггера & сц. счетчики & ЭКсп-ты \\
\hline 1 & $\begin{array}{l}\text { L1_BMU10_BSUR_TSUO_\&_CLC } \\
\text { - } \text { L2_CJET15_L1_BMU10_BSUR_TSUO } \\
\text { o L3_CENTRAL_JET_20 } \\
\text { - MUON_CENTRAL_JET20_L1_BMU10_BSUR } \\
\text { - } \text { MUON_BMU_1 }\end{array}$ & $\begin{array}{l}\text { BSUR и TSU } \\
1.25<|\eta|<1.5\end{array}$ & {$[5-7,10]$} \\
\hline 2 & $\begin{array}{l}\text { L1_BMU10_BSU_PT11 } \\
\text { • } \text { L2_CJET15_L1_BMU10_BSU_PT11 } \\
\text { o L3_CENTRAL_JET_20 } \\
\text { - MUON_CENTRAL_JET20_L1_BMU10_PT11 } \\
\text { - MUON_BMU_1 } \\
\text { • } \text { L2_RL2HZ_L1_BMU10_BSU_PT11 } \\
\text { o L3_BMU9 } \\
\text { - MUON_BMU9_L1_BMU10_BSU_PT11 } \\
\text { - MUON_BMU_1 }\end{array}$ & $\begin{array}{c}\text { BSUF }_{F} \\
1.0<|\eta|<1.25\end{array}$ & $\begin{array}{l}{[5-7],[10,} \\
14]\end{array}$ \\
\hline 3 & $\begin{array}{c}\text { L1_CMU1.5_PT1.5_\&_CMX1.5_PT2_CSX } \\
\text { •L2_CMU1.5_PT1.5_\&_CMX1.5_PT2_DPHI120_OPPQ } \\
\text { o L3_JPSI_CMUCMX } \\
\text { - JPSI_CMU1.5_CMX2 } \\
\text { - JPSIMUMU_1 } \\
\text { o L3_LOWMASS_CMUCMX_SUMPT } \\
\text { - RAREB_CMUCMX_SUMPT } \\
\cdot \text { B_RARE_1 } \\
\text { L2_CMU6_PT4_\&_CMX1.5_PT4_CSX } \\
\text { o L3_DIMUON_CMU4CMX4 } \\
\cdot \text { DIMUON_CMU4_CMX4 } \\
\cdot \text { SUSY_DILEPTON_2 }\end{array}$ & $\begin{array}{c}\text { CSX и MSK } \\
0.6<|\eta|<1.0\end{array}$ & {$[10,14]$} \\
\hline 4 & $\begin{array}{l}\text { L1_CMX6_PT8_CSX } \\
\text { • L2_AUTO_L1_CMX6_PT8_CSX } \\
\text { o L3_CMX8_TRACK5_ISO } \\
\text { - TAU_CMX8_TRACK5_ISO } \\
\text { - TAU_LEPTON_1 } \\
\text { - L2_CMX6_PT15_JET10 } \\
\text { o L3_MUON_CMX18 } \\
\text { - } \quad \text { MUON_CMX18 } \\
\text { - HIGH_PT_MUON_1 }\end{array}$ & $\begin{array}{c}\text { CSX и MSK } \\
0.6<|\eta|<1.0\end{array}$ & $\begin{array}{l}{[5-7,9,} \\
13,14]\end{array}$ \\
\hline 5 & $\begin{array}{l}\text { Используются в “off-line” анализе, } \\
\text { подготавливаются к включению в “on-line” триггер }\end{array}$ & $\begin{array}{c}\text { CSP и CSP Wall } \\
0<|\eta|<0.6\end{array}$ & $\begin{array}{l}{[5-7,9,10]} \\
{[12-14,16]}\end{array}$ \\
\hline
\end{tabular}


б) три струи с $E_{T}>15$ Гэ $B$ и четвертая струя с $E_{T}>8$ Гэ $B$ при условии, что одна струя с $E_{T}>15$ Гэ $B$ идентифицирована как кандидат на $b$ кварк, т.е. с нахождением вторичной вершины от распада "bottom" адрона ( $b$ tag).

Таким способом было отобрано 165 событий - кандидатов на образование $t \bar{t}$ - пары.

Измерение массы топ кварка проводилось двумя способами на $318 p b^{-1}$ набранной статистики. Первый способ, известный как DLM [6] (dynamical likelihood method) использует метод наибольшего правдоподобия в каждом отдельно взятом событии для определения массы топ кварка как функции основного матричного элемента продуктов $t \bar{t}$ распадов, т.е. определяется дифференциальное сечение на единицу фазового объема оконечного состояния партонов $d \sigma_{t} / d \Phi$, как функция $M_{\text {top. }}$. В конечном результате получаем “объединенную” функцию правдоподобия, определяющую массу топ кварка $M_{\text {top }}$ перемножением функций наибольшего правдоподобия от отдельных событий. Второй способ использует реконструкцию массы каждого топ кварка $m_{t}^{\text {reco }}$ и последующее сравнение распределения $m_{t}^{\text {reco }} \mathrm{c}$ “шаблонными” распределениями с примесью фона, полученными путем моделирования для набора масс топ кварка $M_{\text {top }}=(140 \div 220) \Gamma \ni B / c^{2}$ [5].

На рис. 4 показано распределение значений масс $t$-кварка, определенных DLM методом на статистике 63 события. Значение $M_{\text {top }}=173,2_{-2,4}^{+2,6}$ (stat.) $\Gamma \ni B / c^{2}$ определено как максимум функции правдоподобия.

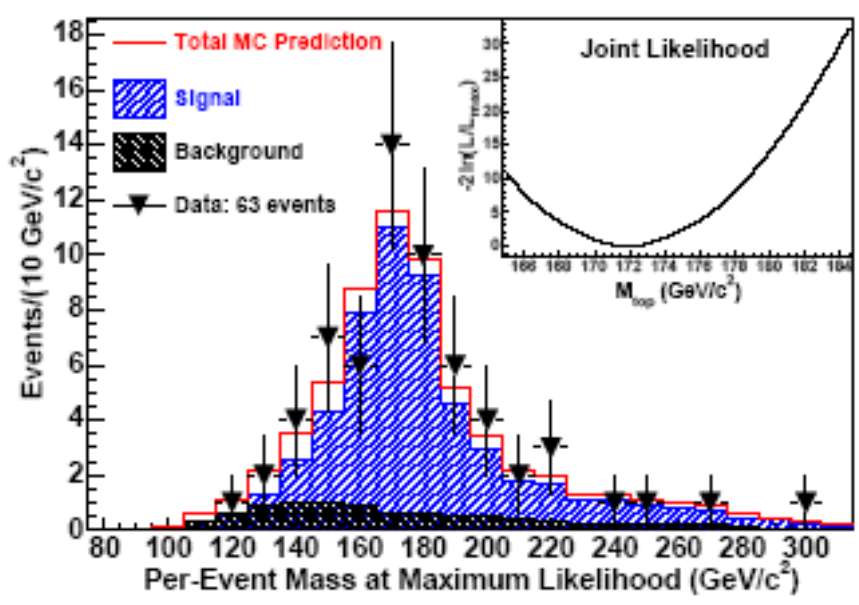

Рис.4. Масса топ кварка как максимум функции (DLM) правдоподобия.

Экспериментальные данные (точки) сравниваются с ожидаемым распределением (гистограмма), полученным моделированием $t \bar{t}$ $\left(M_{\text {top }}=172,5\right.$ Гэ $\left.B / \mathrm{c}^{2}\right)$ распадов и фоновых событий [6].

Систематическая погрешность оценена как сдвиг $M_{\text {top }}$, полученный изменением (JES) энергетической шкалы струй на $1 \sigma_{c}$ и составляет 3,0 Гэ $B / c^{2}$ [6].

Рис. 5 иллюстрирует распределение значений массы топ кварка, определенных методом шаблонов. Во всех случаях видна согласованность гистограмм с фитированной кривой. Получен результат $M_{\text {top }}=173,5_{-3,6}^{+3,7}$ (stat.) 
Гэ $B / c^{2}$, где статистическая погрешность включает неопределенность в JES, оцененную в $\approx 2,5 \Gamma \ni B / \mathrm{c}^{2}[5]$.

В числе существенных результатов инициированных и достигнутых при активном участии автора новых разработок, в данной главе указываются следующие:
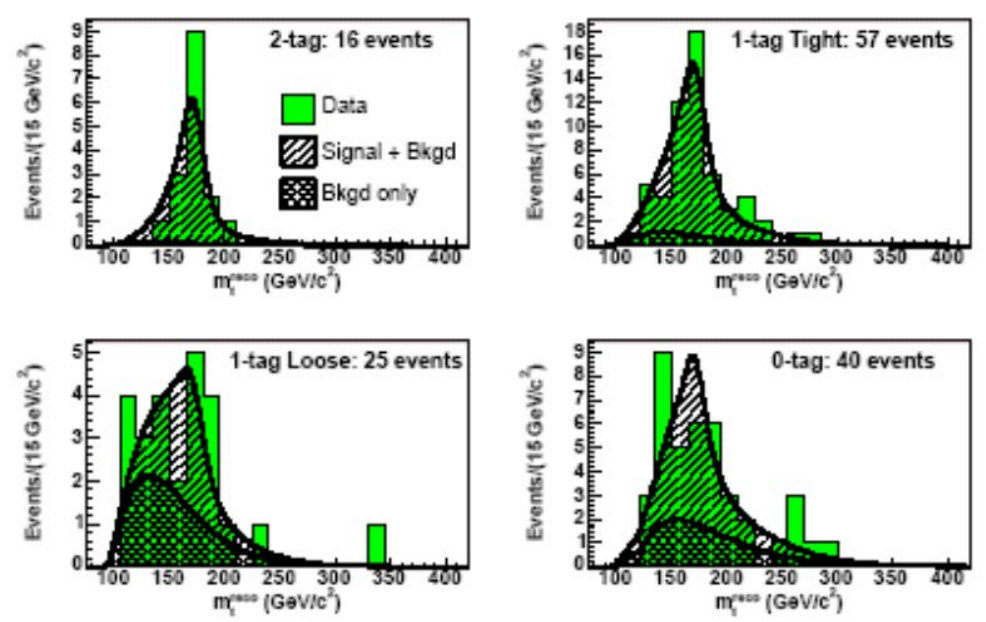

Рис.5. Распределение $m_{t}^{\text {reco }}$, полученное методом шаблонов, аппроксимировано ожидаемым распределением, полученным комбинированным фитом с использованием $M_{\text {top }}$, JES и нормированных сигналов и фона [5].

- Программа «MuonMonitor», разработанная и созданная на основе программного пакета Visual C++ и Visual Basic от фирмы Microsoft, сделала возможным управление работой всех устройств, распределяющих высокое напряжение. Создана ранее отсутствовавшая электронная база данных по основным параметрам сцинтилляционных счётчиков, обращаясь к которой, программа «MuonMonitor» может самостоятельно выставлять заданные высокие напряжения ФЭУ и уровни порогов на дискриминаторах.

- Созданная на основе программного обеспечения iFIX $^{6}$ программа «MuonMain», ранее, до начала наших разработок, отсутствовавшая на CDF, интегрирована в глобальную систему контроля и в режиме реального времени контролирует заданные параметры мюонных сцинтилляционных счётчиков. Каждые 15 минут в течение 30 секунд происходит мониторирование высокого напряжения $\approx 1200$ ФЭУ и порогов 551 предусилителя.

- Кроме вышеописанных программных решений применяется встроенная в глобальную систему контроля CDF система оперативного контроля состояния отдельных устройств: распределителей-приёмников высокого напряжения и информации, источников и раветвителей высокого напряжения, всех задействованных КАМАК крейтов, базисного компьютера контроля и управления.

\footnotetext{
${ }^{6}$ iFix - лицензионный пакет программ фирмы «Intellution»
} 
- Разработанное программное обеспечение для контроля долговременной стабильности параметров счетчиков позволяет выявлять отдельные либо группу счётчиков с низкой эффективностью. Рисунок 6 иллюстрирует эффективность счетчиков CSP Wall, полученную сравнением количества срабатываний счетчиков и треков, проведенных в соответствующих дрейфовых камерах CMP/CMU. В случае наблюдения низкой эффективности счетчиков определяются причины неисправностей и устраняются.

Вышеописанные меры обеспечили достижение и поддержание стабильной эффективной работы сцинтилляционных счетчиков мюонной системы CDF II в длительных сеансах набора физических данных.
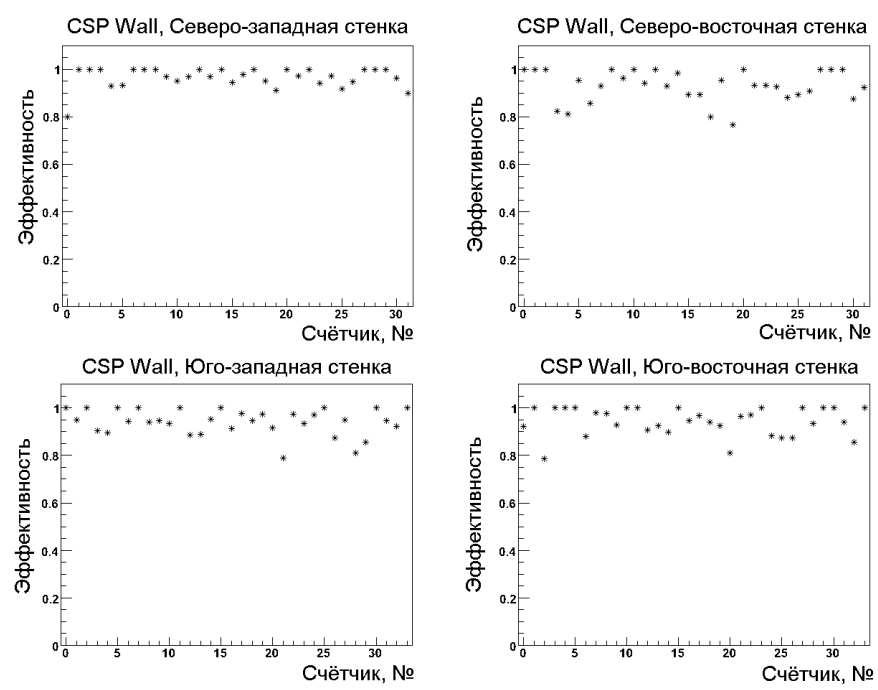

Рис. 6. Эффективности счётчиков CSP Wall.

Созданный аппаратно-программный комплекс сбора данных, управления параметрами и оперативного контроля обеспечил эффективное функционирование сцинтилляционных счётчиков мюонного триггера CDF II при наборе физических данных в проводимом ныне на Тэватроне сеансе Run II и внес вескую лепту в получение важных новых результатов принципиального научного значения по физике $c, b, t-$ кварков, $B_{s}^{0}-\bar{B}_{s}^{0}$ смешиванию, и т.д. В частности, среди результатов подобного класса, достигнутых с применением созданных детекторов мюонного комплекса $\mathrm{CDF}$, измерение массы $t$-кварка, приведенное выше [5, 6], другое измерение этой величины $M_{\text {top }}=170.1$ Гэ $B / c^{2} \pm 6.0$ (stat.) \pm 4.1 (syst.) [7] в т.н. “дилептонной” моде, наиболее точное измерение массы W-бозона $M_{W}=80413 \pm 48$ (stat.) $M э B / c^{2}[16]$, ряд существенных проверок СМ $[10,13,14]$ и др. В получении этих результатов определяющую роль играла высокая эффективность регистрации электронов (до $96 \%$ ) и мюонов (до $90 \%$ ).

В третьей главе описывается принцип работы, исследование основных параметров [4] и технология массового изготовления сцинтилляционных счётчиков нового поколения на основе украинского сцинтиллятора 
UPS 923A со светосбором спектросмещающими волокнами, впервые примененных нами в коллайдерных экспериментах [3, 11].

Оптоволоконный съём света (рис. 7) имеет важные преимущества в сравнении с классическим методом сбора света плексигласовыми световодами, главными из которых являются компактность (уменьшение нечувствительной зоны детектора), использование миниатюрного (т.е. возможность применения в сильных магнитных полях без дополнительной экранировки) ФЭУ и долговременная эффективность (т.е. меньшая зависимость светосбора от естественной деградации сцинтиллятора со временем).

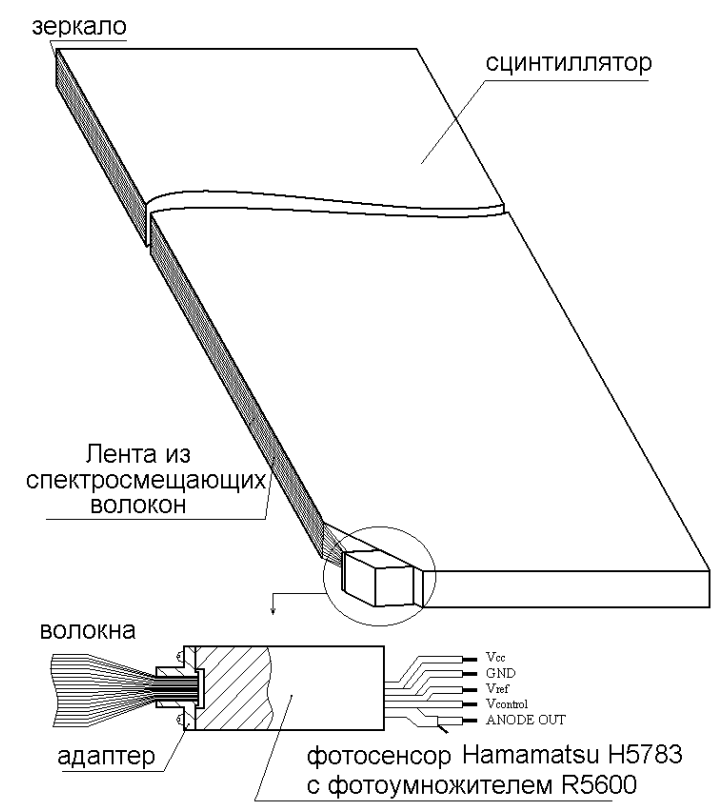

Рис. 7. Схематический вид сцинтилляционных счётчиков со съёмом света оптоволоконной лентой.

Сбор света в сцинтилляционных счетчиках нового поколения происходит следующим образом: часть голубого света, излученного сместителем спектра РОРОР, достигая оптоволоконной ленты, поглощается добавкой Ү11 (или K27) и изотропно переизлучается в более длинноволновую зеленую область. Использовались многооболочечные спектросмещающие волокна S-типа фирмы KURARAY и фирмы Pol.Hi.Tech, включающие добавки Y11 (250 ppm) и К27 (200 ppm) соответственно [3].

Переизлучённый свет распространяется по волокнам к ФЭУ и к противоположному от ФЭУ концу (рис. 7). Зеркало на дальнем торце волоконной ленты увеличивает на $60 \%$ светосбор. Типичная квантовая эффективность фотосенсора $\mathrm{H} 5783$ равна $\approx 12 \%$ на длине волны излучения сместителя спектра Ү11 или К27 ( 500 нм).

Мы провели серию исследований следующих свойств сцинтиллятора UPS 923А: световыход, ослабление света и долговременная стабильность [4]. Также измерены временные характеристики сцинтиллятора и спектросмещающих волокон [11]. 
Отметим, что при сравнимых значениях TAL пластин из UPS 923A и NE 114 (на основе последнего изготовлены старые счетчики CDF) светосбор с первой из них приблизительно на 25 \% больше (рис. 8).

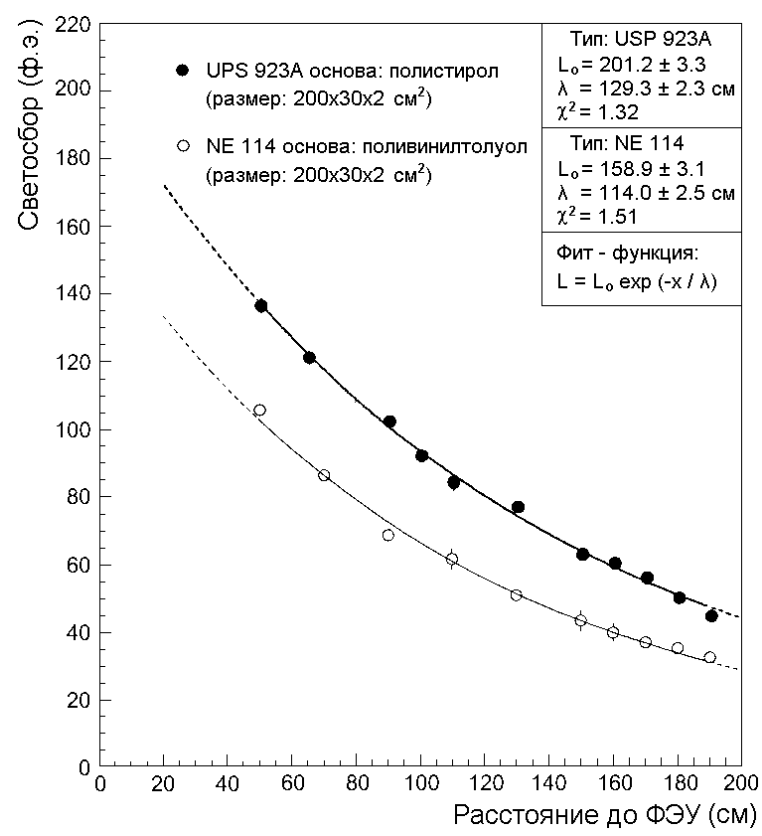

Рис. 8. Светосбор со счётчиков в зависимости от расстояния до ФЭУ.

Впервые нами предложен и разработан метод измерения объемной длины ослабления сцинтиллятора (BAL) к собственному излучению. Экспериментально показано, что BAL к собственному излучению не является постоянной величиной и сильно зависит от пути распространения света в сцинтилляторе из-за эффекта реабсорбции (рис. 9).

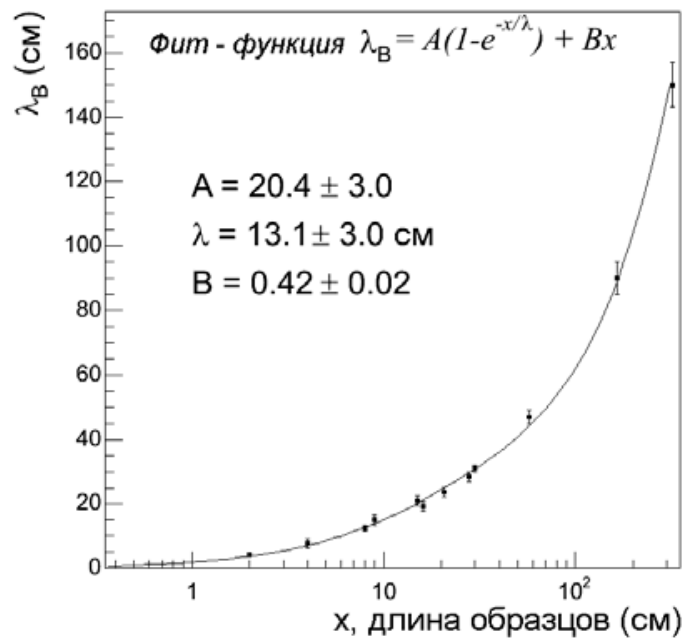

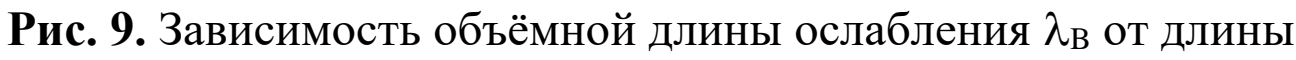
сцинтиллятора.

Изучение формы светового импульса однофотонным методом Боллингера и Томаса показало: нарастание импульса света от сцинтиллятора UPS 923A 
со спектросмещающими волокнами - быстрое $(\approx 2 \mu c)$, поэтому счётчики с подобным методом съёма света могут быть использованы в быстрых системах совпадений и для времяпролётных измерений.

Наши исследования естественного старения сцинтилляторов UPS 923A на основе полистирола и NE 114 на основе поливинилтолуола, показали: естественная деградация сцинтиллятора NE 114 идет более чем в два раза быстрее, чем сцинтиллятора UPS 923A из-за различия в химической структуре полимерной основы сцинтилляторов (рис. 10).
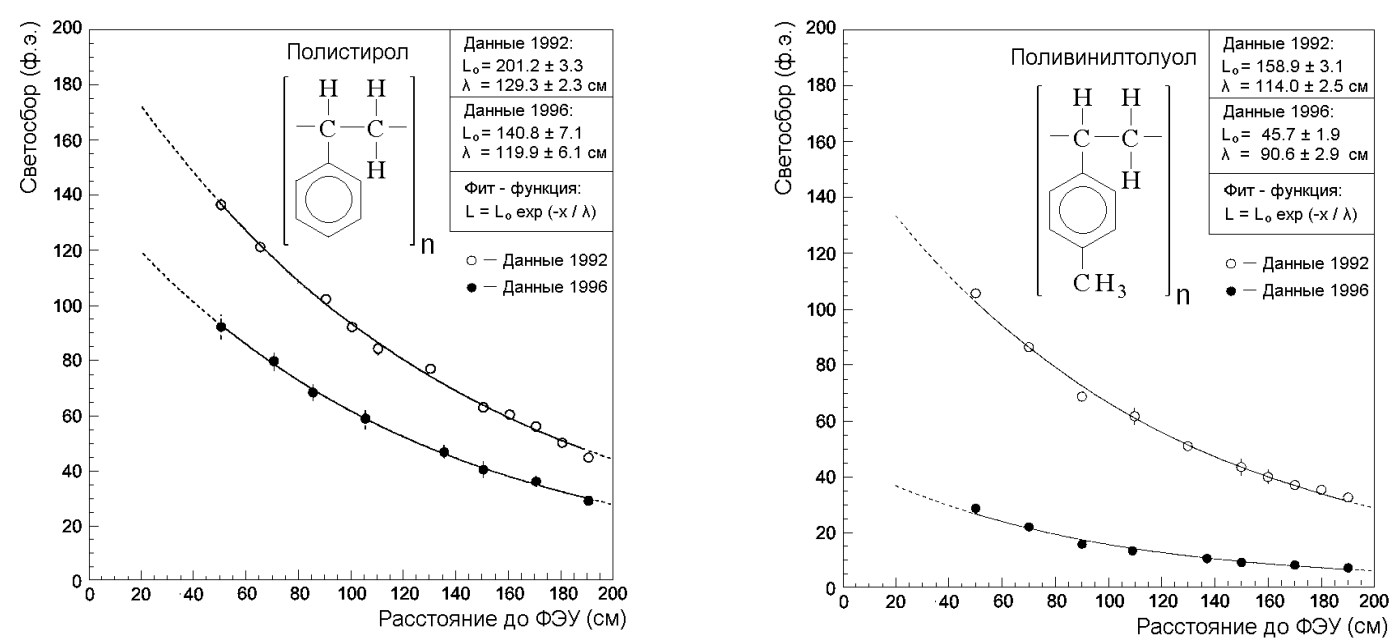

Рис. 10. Зависимость светосбора сцинтилляционного счётчика на основе, полистирола (UPS 923A) - слева и поливинилтолуола (NE 114) - справа, от расстояния до ФЭУ.

По результатам исследований сцинтиллятор UPS 923A был выбран для развития мюонной системы детектора CDF на Теватроне Фермилаб.

Для массового изготовления детекторов разработан специальный универсальный сборочный стапель [3], на котором возможна приклейка волокон к сцинтилляционным пластинам толщиной 1.5 и 2 cм (рис. 11). Для достижения максимально ровной поверхности стапеля мы использовали свойство жидкости (эпоксидного клея), растекаться под действием силы тяжести в ровную поверхность.
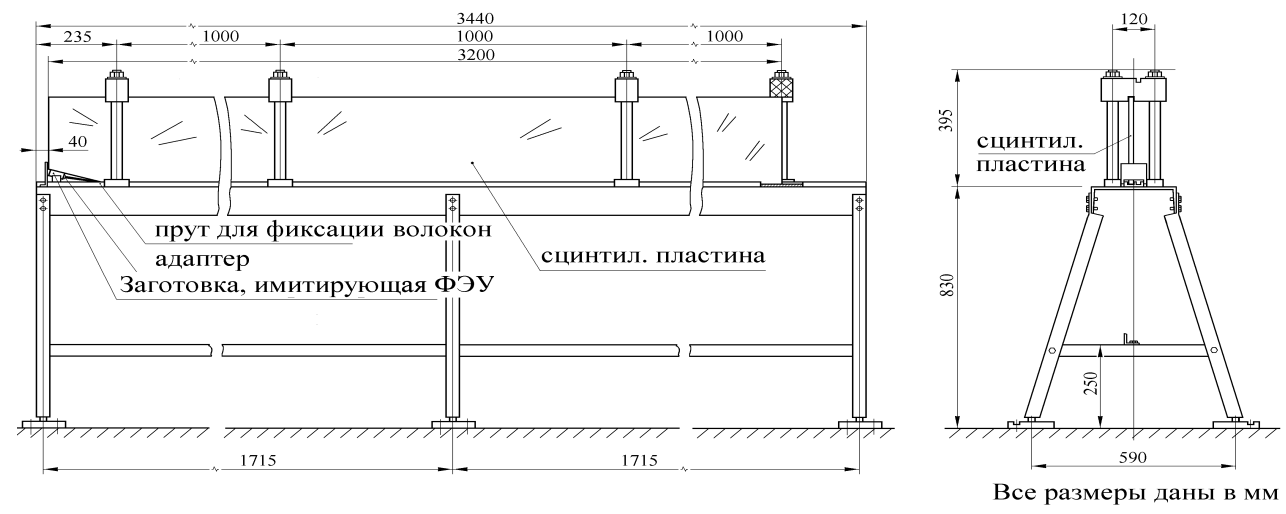

Рис.11. Стапель, разработанный для массового изготовления счетчиков (вид спереди и сбоку). 
Исследования созданных счётчиков по светосбору нами проводились в ОИЯИ и в Фермилаб на космических мюонах методом абсолютной калибровки ${ }^{7}$ (рис. 12). На рисунке 13 показаны распределения светосбора в фотоэлектронах (ф.e.) для счётчиков BSU и CSP при прохождении космических мюонов через пластину в дальнем от ФЭУ конце счётчиков.

Таким образом, сумма выполненных работ по созданию более 600 счётчиков нового поколения обеспечила достижение существенного результата: аксептанс мюонной системы установки CDF увеличен значительно - на $60 \%$.

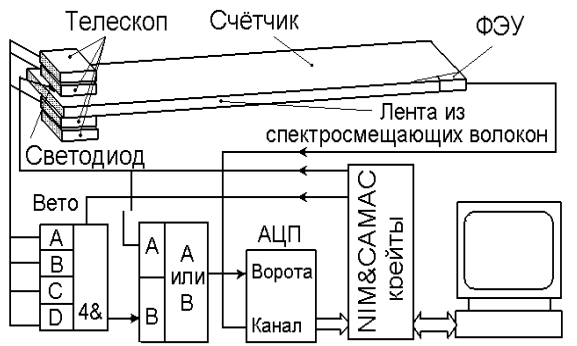

Рис. 12. Блок-схема аппаратуры для измерений светосбора с дальнего от ФЭУ конца счётчика.
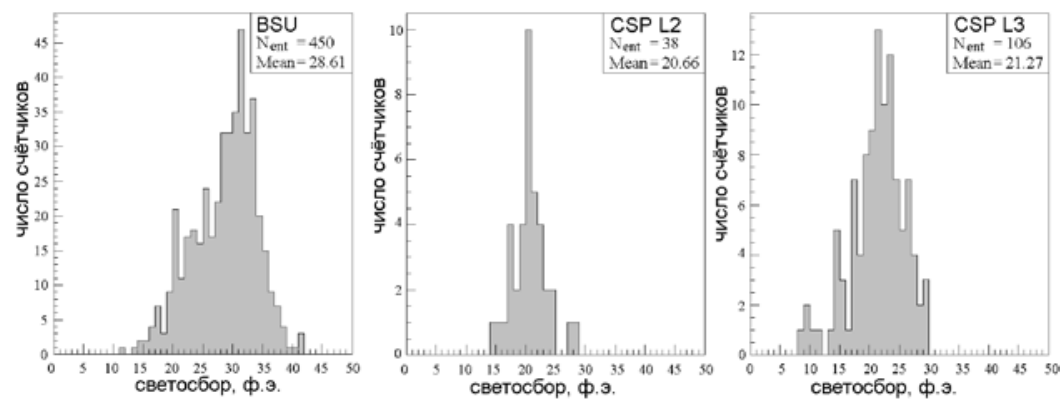

Рис. 13. Светосбор с дальнего от ФЭУ конца для сцинтилляционных счётчиков BSU, CSP L2 и CSP L3 типов, изготовленных в ОИЯИ.

В четвёртой главе описываются связанные с повышением светимости Тэватрона: разработка и создание нового многоканального основанного на пластическом сцинтилляторе преконвертора CPR2 [20, 21] электромагнитного калориметра, изучение нового мюонного триггера в области $1.0 \leq|\eta| \leq 1.25$ [18], а также исследование старения сцинтилляционных счётчиков мюонного триггера CDF II [15, 19].

Преконвертор электромагнитного калориметра CPR2.

Повышение светимости Тэватрона привело к необходимости замены старого преконвертора: так, уже с началом сеанса Run II его использование стало проблематичным. Между тем преконвертор играет весьма значительную роль в разделении частиц и точности измерения их кинематических параметров. Эти качества существенны во многих исследованиях по физике тяжелых кварков, распадов W, Z бозонов и т.д.

Основные причины замены преконвертора, следующие:

- в сеансе Run I старый преконвертор базировался на относительно медленных проволочных газовых детекторах - пропорциональных камерах и работал при светимости до $1.0 \times 10^{32} \mathrm{~cm}^{-2} \mathrm{c}^{-1}$. С увеличением светимости до $2.0 \times 10^{32} \mathrm{~cm}^{-2} \mathrm{c}^{-1}$ и выше такие детекторы работают с трудом или вообще перестают справляться со своей задачей;

\footnotetext{
${ }^{7}$ E. H. Bellamy et al. Absolute Calibration and Monitoring of a Spectrometric Channel Using a Photomultiplier. // Nuclear Instruments \& Methods. - Amsterdam, 1994. - A339. - P. 468-476.
} 
- амплитуда импульса сильно уменьшилась из-за деградации сигнальной проволочки;

- необходимость увеличения быстродействия и улучшения энергетического разрешения электромагнитного калориметра требовала большей сегментации преконвертора по псевдобыстроте $\eta$, которая в созданном детекторе выросла почти на порядок.

В новом преконверторе детектирующие элементы нами заменены: ими стали тайлы - сцинтилляционные пластины с размерами 125x125x20 мм² (рис. 14) [20, 21]. Изготовлено, тестировано и отобрано более 3000 тайлов со стабильно высоким световыходом до 36 ф.э. на минимально ионизирующую частицу (МИЧ), а это, в свою очередь, обеспечило регистрацию не менее 12 ф.э./МИЧ (в среднем) после прохождения всего оптоволоконного тракта (до 5 ). Последняя величина превышает более чем в два раза уровень 5ф.э./МИЧ, минимально необходимый для эффективной регистрации калориметром одиночной частицы ${ }^{8}$.

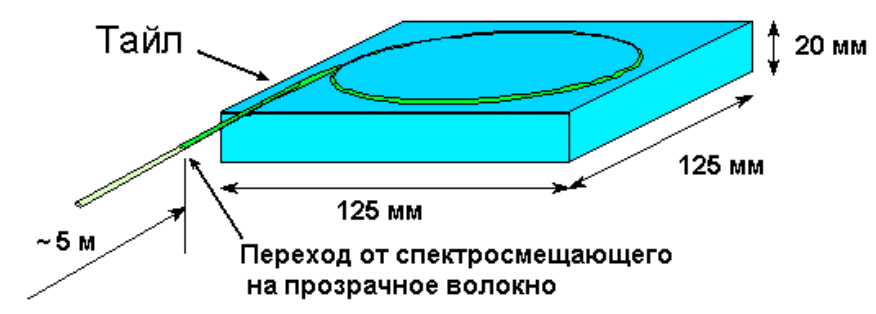

Рис. 14. Сцинтилляционная пластина (тайл).

Нами решена главная задача: массовое и контролируемое по светосбору производство тайлов в Дубне и в Харькове. Изготовление канавки для оптоволокна было последним этапом перед сборкой модуля CPR2 в CША.

Для обеспечения надлежащего качества тайлов необходимо было определение светосбора (от МИЧ) для тайла без канавки, соответствующего светосбору не менее $18 \not$.э./МИЧ со спектросмещающего оптоволокна, установленного в $\Omega$-образной канавке на поверхности тайла. Была проведена серия контрольных измерений для решения этой задачи.

Суть методики, применённой в ОИЯИ, такова. Вначале измерялся светосбор (в ф.э.) с проектируемым методом съёма света при помощи оптоволокна и фотоэлектронного умножителя (ФЭУ). На втором этапе ФЭУ был приставлен непосредственно к одному из узких торцов тайла и определялся светосбор (в ф.э.) с исследуемой пластины. Сравнение полученных величин определило опорный параметр для отбора тайлов. Для проведения исследований было изготовлено несколько прототипов тайлов из сцинтилляционных пластин разного качества (рис. 15).

Кроме этого, использовался радиоактивный источник $\mathrm{Sr}^{90}+\mathrm{Y}^{90}$, излучение которого коллимировалось в пучок диаметром 1 мм. Облучение

${ }^{8}$ R. Blair et al. Proposal to replace the Central Preshower Detector and Central Crack Chambers with an integrated scintillator detector (CPR2). // CDF Note. - Batavia, 2001. - CDF/DOC/CALORIMETRY/CDFR/5519. - P. 12. 
производилось перпендикулярно большой поверхности тайла на фиксированных расстояниях от ФЭУ, приставленного к узкой грани пластины, и измерялся анодный ток. Этот метод традиционно используется в "Институте Монокристаллов"9 для определения параметров производимых сцинтилляционных пластин. Были проведены исследования для согласования оценок светосбора, измеренного с использованием радиоактивного источника и методом абсолютной калибровки, с целью выработки опорного параметра для контроля качества тайлов, производимых в Харькове (рис. 16).

Описанные выше методики контроля качества позволили нам в сжатые сроки изготовить более 3000 тайлов с высоким (до 36 ф.э.) светосбором [20, 21].

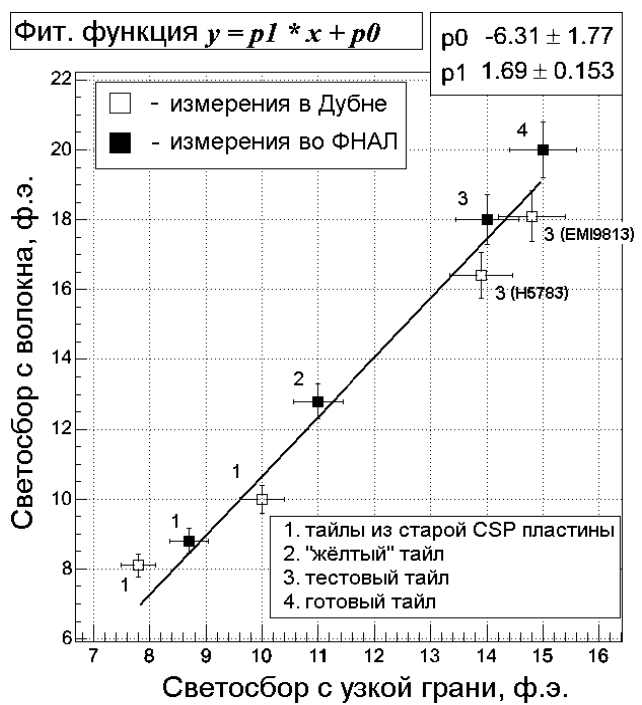

Рис. 15. Корреляция светосбора со спектросмещающего оптоволокна и с узкой грани тайла

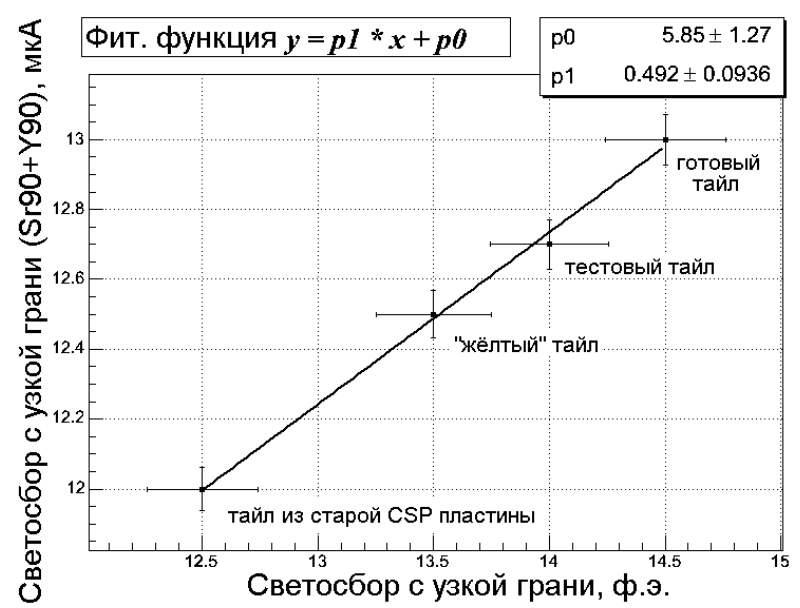

Рис. 16. Корреляция светосбора с узкой грани тайла, измеренного разными способами: методом абсолютной калибровки и с помощью радиоактивного источника, который был установлен в центре тайла.

Эффективность нового конвертора CPR2 иллюстрируется ниже.

\footnotetext{
${ }^{9}$ Институт сцинтилляционных материалов НКТ «Институт монокристаллов», г. Харьков, Украина.
} 
На рисунке 17 (слева) показано распределение по выделенной в преконверторе энергии для кандидатов на мюоны от распадов $W$-бозонов, после введения поправок трактов усиления сигналов с тайлов. Для сравнения показано распределение от частиц с треками с поперечной энергией $p_{t}$ более 8 Гэ $B$, которые иногда образуются от взаимодействия продуктов протонантипротонных столкновений с материалом перед детектором CPR2.

Кроме минимально ионизирующих частиц детектор CPR2 зарегистрировал также большое количество электронов от распадов $W$ бозонов. На рис.17 (справа) показано распределение для кандидатов на электроны от распадов $W$-бозонов в сравнении с аналогичным предыдущему распределением от случайных частиц. Видно, что при пороге 5 ф.э. будут регистрироваться практически только одни электроны.
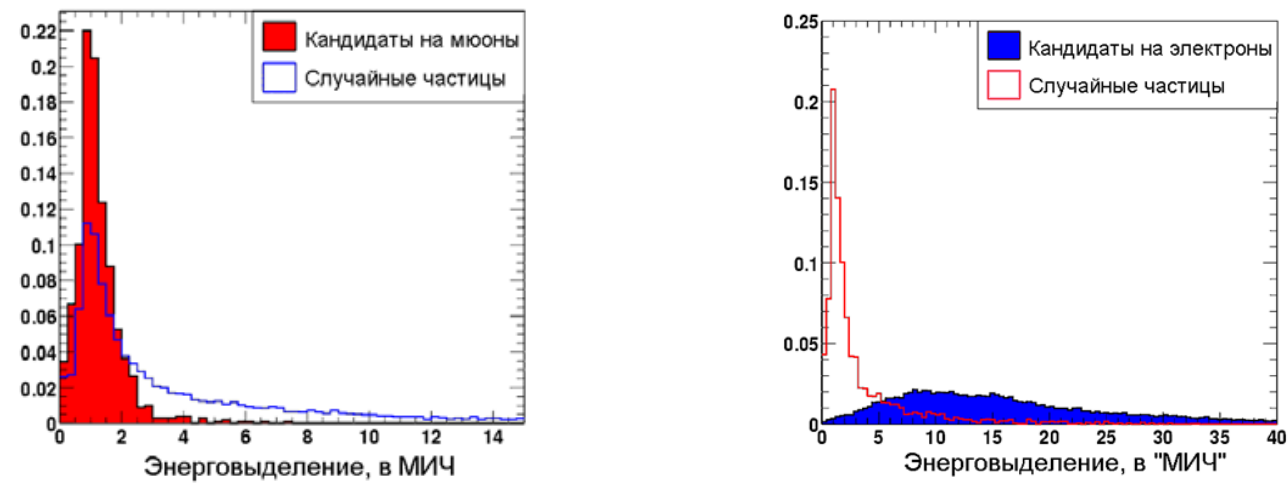

Рис. 17. Распределение по выделенной в преконверторе энергии (в единицах МИЧ) для кандидатов на мюоны от распадов $W$-бозонов и от случайных треков с поперечной энергией $p_{t}$ более 8 Гэ $B$ (левый рисунок). То же для кандидатов на электроны от распадов $W$-бозонов и от случайных частиц с поперечной энергией $p_{t}$ более 8 ГэВ (правый рисунок).

Таким образом, сохранив достоинства старого преконвертора:

- 2-3 кратное увеличение подавления фона от заряженных пионов, что крайне важно при последующей идентификации электрона для $b$-jet мечения,

- возможность идентификации одиночных фотонов (на фоне мезонов) в области энергий больше 35 ГэВ,

- улучшение энергетического разрешения струй, что очень существенно для поиска или экспериментального сужения вероятного интервала масс частиц Хиггса;

новый преконвертор обладает принципиально новыми качествами:

- работает при светимости до $3.0 \times 10^{32} \mathrm{~cm}^{-2} \mathrm{c}^{-1}$ и выше;

- имеет на порядок более высокую гранулярность по псевдобыстроте;

- имеет на порядок более высокое быстродействие, что очень важно в свете планируемого уменьшения интервала между сгустками сталкивающихся протонов и антипротонов с 396 до 132 нс. 
Исследование эффективности нового мюонного триггера в области $\underline{1.0 \leq|\eta| \leq 1.25 \text {. }}$

Увеличение светимости Тэватрона до $2 \times 10^{32} \mathrm{~cm}^{-2} c^{-1}$ и связанное с этим ужесточение требований отбора полезных событий привели к исключению из списка триггеров, обязательных на установке CDF II, мюонного триггера первого уровня (L1) в области $1.0 \leq|\eta| \leq 1.25$ (потери $\sim 10 \%$ ). Нами предложен вариант восстановления данного триггера путём включения в него сигналов с дополнительного слоя мюонных сцинтилляционных детекторов (рис. 18) [18].

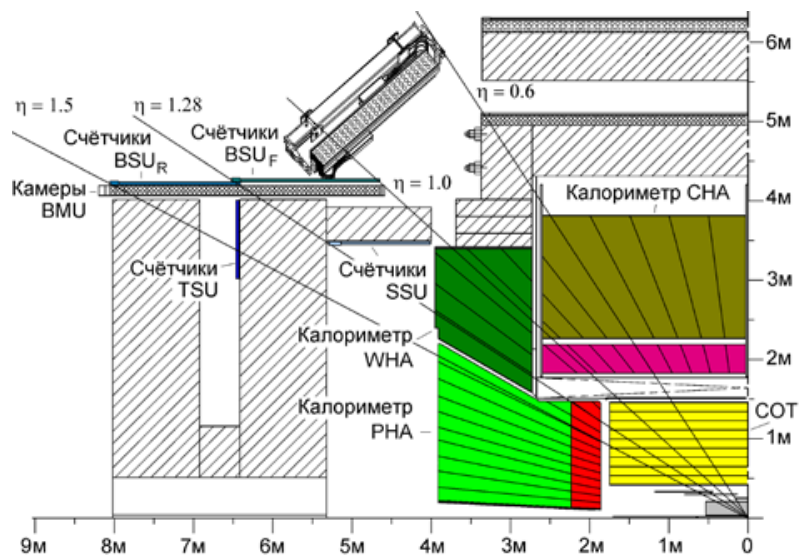

Рис. 18. Расположение детекторов мюонного триггера в области $1.0 \leq|\eta| \leq 1.5$, а также место предполагаемой установки нового слоя сцинтилляционных счётчиков SSU.

Для оценки ожидаемого эффекта от включения счётчиков SSU в триггер мы обработали данные, отобранные глобальным общим триггером установки CDF на протяжении 3 месяцев сеансов набора с мая по июль 2005 года.

На рис.19 показаны распределения событий по счётчикам и времён прихода событий, отобранных предложенным триггером. Следует отметить резкое выделение пиков в области 160 нс от начала отсчёта - этот пик для счётчиков SSU приходится на 157 нс (нижний левый рисунок) и для счётчиков BSU приходится на 160 нс (нижний правый рисунок) от начала отсчёта и разница составляет около 3 нс (верхний правый рисунок). Если учесть, что время пролёта от счётчика SSU до счётчика BSUF для заряжённой частицы, летящей из зоны протон-антипротонных столкновений, должно составлять 3 нс, то можно полагать, что на эти пики приходятся именно мюоны, рождающиеся в искомых событиях в центре установки.

Для сравнения приведём распределение времён приходов событий для счётчиков $\mathrm{BSU}_{\mathrm{F}}$, соответствующих мюонам при исследовании распадов $\mathrm{Z}$-бозонов $\left(\right.$ рис. 20) ${ }^{10}$. Среднее положение пика для счётчиков BSUF 159 нс, то есть совпадает с положением пиков на гистограммах при отборе событий предложенным нами триггером. Это подтверждает высокую эффективность нового триггера при отборе мюонов, рождённых в центре установки CDF.

${ }^{10}$ D. Cyr et al. CDF Intermediate Muon Trigger. // CDF Note. - Batavia, 2005. - CDF/DOC/TRIGGER/CDFR/7694. - P. 31. 
Более того, проведённый анализ показал: а) идентичность предлагаемого мюонного триггера L1 в области $1.0 \leq|\eta| \leq 1.25$ ныне используемому мюонному триггеру в области $1.25 \leq|\eta| \leq 1.5$; б) суммарная частота триггера L1 для области $1.0 \leq|\eta| \leq 1.5$ не превышает допустимого на CDF II уровня - $1 \kappa Г u$.

Полученные нами данные подтвердили целесообразность предлагаемого решения: увеличение аксептанса мюонного триггера уровня L1 возможно путём установки дополнительного слоя сцинтилляционных счётчиков в области $1.0 \leq|\eta| \leq 1.25$ [18].
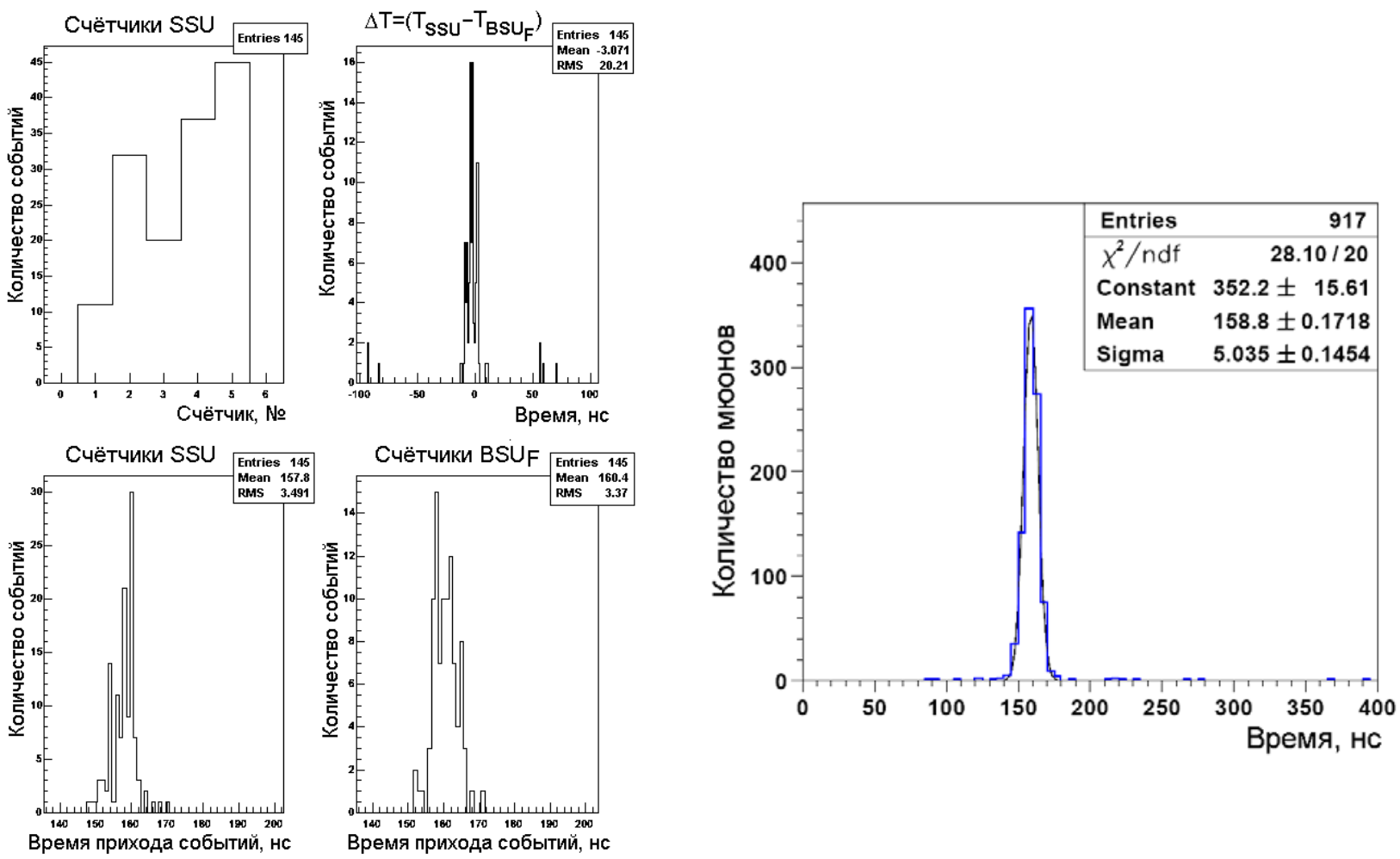

Рис. 19. Распределение событий по счётчикам, а также времён прихода этих событий и разности времён приходов для соответствующих пар счётчиков BSU и SSU при предложенном новом мюонном триггере в области $1.0 \leq|\eta| \leq 1.25$.

Рис. 20. $\mathrm{BSU}_{\mathrm{F}}$ счётчики: распределение по времени прихода событий, соответствующих мюонам при исследовании распада $Z \rightarrow 2 \mu$.

Исследование старения сцинтилляиионных счетчиков мюонного триггера CDF II.

Проведённое нами исследование процесса старения, то есть измерение уменьшения светосбора со временем, сделало возможным для коллаборации CDF прогнозировать долговременную эффективность использования сцинтилляционных детекторов $[15,19]$. Мюонная система установки CDF включает более 1140 сцинтилляционных счётчиков разного типа. Часть этих 
счётчиков осталась со времени сеанса Run I, другая часть была создана специально в рамках модернизации установки CDF перед сеансом Run II.

Были выполнены систематические измерения параметров одного и того же набора счётчиков разного типа. Исследовано в общей сложности до 60 счётчиков (см. табл. 2). Счётчики CSP и BSU, изготовленные в Дубне, представляют собой счётчики нового поколения с оптоволоконным съёмом света, размерами $3200 \times 305 \times 20$ м. $^{3}$ и $1638 \times 166 \times 15$ м. $^{3}$ соответственно. Основа сцинтиллятора - полистирол (ПС). Счётчики CSP Wall - это так называемые "модернизированные" счетчики со смешанным способом сбора света, с размерами $3200 \times 320 \times 20$ мм $^{3}$. Счётчики CSX имеют трапециидальную форму, с размерами $1800 \times(300,400) \times 25$ мм $^{3}$, съём света производится классическим способом - с помощью плексигласовых световодов. Основа сцинтиллятора для счётчиков CSP Wall и CSX - поливинилтолуол (ПВТ).

Таблица 2.

Основные результаты исследования естественного старения сцинтилляционных счётчиков установки CDF II.

\begin{tabular}{|c|c|c|c|}
\hline Тип счётчика & Основа & Кол-во & $\begin{array}{c}\text { Постоянная старения } \tau \\
\text { (годы) }\end{array}$ \\
\hline CSP Wall & ПВТ & 23 & $4.7 \pm 0.3$ \\
\hline CSX & ПВТ & 17 & $7.6 \pm 1.3$ \\
\hline BSU & ПC & 17 & $12.4 \pm 1.0$ \\
\hline CSP & ПC & 2 & $8.9 \pm 0.9$ \\
\hline
\end{tabular}

Методом абсолютной калибровки в течение нескольких лет периодически измеряется светосбор с дальнего от ФЭУ конца сцинтилляционной пластины. Далее экспериментальные данные аппроксимируются ординарной экспоненциальной функцией (рис. 21, табл. 2).

Проведенный цикл исследований позволил получить ранее отсутствовавшие сведения по старению сцинтилляционных счётчиков установки CDF II в условиях реального эксперимента и интегрального учёта многих факторов, влияющих на деградацию сцинтилляционной пластины.

В том числе: a) статистически достоверно установлено, что скорость деградации поливинилтолуольного сцинтиллятора почти вдвое выше, чем у полистирольного сцинтиллятора аналогичной геометрии; б) для полистирольных сцинтилляционных счётчиков нового поколения в системе "сцинтиллятор + оптоволокно" определяющим является старение пластика (вклад оптоволокна в уменьшение светосбора с дальнего от ФЭУ конца не превышает 20\%); в) техническая длина ослабления для сцинтилляционных счетчиков с оптоволоконным способом съёма света слабо зависит от времени. Центральный вывод наших исследований: определено, что счетчики, изготовленные в ОИЯИ, могут быть использованы для набора 
статистики без заметного уменьшения эффективности до конца сеанса Run II $[15,19]$.

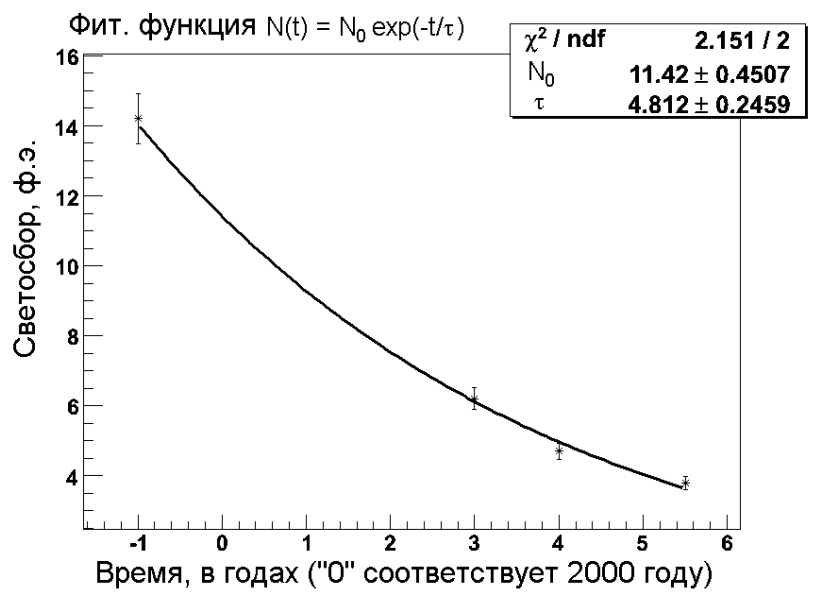

Рис. 21. Световыход с дальнего от ФЭУ конца для одного из счётчиков CSP Wall по годам.

В заключении сформулированы основные результаты диссертационной работы:

1. Разработаны и созданы крупногабаритные сцинтилляционные счетчики нового поколения, в которых впервые применена техника светосбора спектросмещающими волокнами [3, 4, 11]; ранее подобная техника светосбора применялась только в калориметрах.

Интегрированные в мюонный комплекс CDF, эти счетчики (более 600 штук с общей площадью свыше $250 \mathrm{M}^{2}$ ) радикально, на 60\%, увеличили аксептанс установки для регистрации мюонов, составляющей принципиальную часть большинства триггеров при исследованиях по физике $c, b, t-$ кварков, поиске Хиггс бозонов, явлений за пределами стандартной модели, проявлений суперсимметрии и др.

2. Создана система сцинтилляционных детекторов мюонного комплекса (более 1140 сцинтилляционных счетчиков разных типов), включая системы подачи питания, съема информации [17], управления и контроля [2], которая входит, как принципиальная часть в мюонный триггер реального времени и активно используется в проводимых ныне экспериментах на CDF II, обеспечив получение ряда важных новых результатов принципиального научного значения. В их числе:

- наиболее точное измерение массы топ кварка в т.н. моде “лептон + струи" $M_{t o p}=173,5_{-3,6}^{+3,7}$ (stat.) $\Gamma \ni B / c^{2}[5,6]$

- прецизионное измерение этой величины в т.н. дилептонной моде $M_{\text {top }}=170,1_{-6,0}^{+6,0}$ (stat.) $\Gamma \ni B / c^{2} \pm 4.1$ (syst.) [7]

- наиболее точное измерение массы $W$-бозона $M_{W}=80493 \pm 48$ (stat.) $M \ni B / c^{2}[16]$

- первое наблюдение и измерение частоты $B_{s}^{0}-\bar{B}_{s}^{0}$ осцилляций, $\Delta \mathrm{m}_{\mathrm{s}}=17.77 \pm 0.10$ (stat) \pm 0.07 (syst) $n c^{-1}[8,9]$ 
- высокоточное измерение времени жизни $\Lambda_{b}^{0}$ адрона, $\tau\left(\Lambda_{b}^{0}\right)=$ $=1.593_{-0.078}^{+0.083}$ (stat) $\pm 0.033 n c$ (syst) [12]

- ряд существенных проверок СМ в процессах аномального рождения многомюонных событий [13], измерения сечения образования пары $t \bar{t}[10]$ и спиральности $W$-бозона из распадов $t$-кварков [14].

3. С целью повышения эффективности установки CDF в исследованиях процессов с тяжелыми кварками при возросшей светимости Тэватрона $\left(2 \cdot 10^{32} /\right.$ м $^{2} c$ и выше) создан новый прибор - 2600 канальный годоскопический преконвертор электромагнитного калориметра из сцинтилляционных пластин с размерами $125 \times 125 \times 20$ мм² общей площадью более $40 \boldsymbol{M}^{2}[20,21]$. Его быстродействие и сегментация по псевдобыстроте на порядок превосходят эти величины в сравнении с ранее существовавшей системой - пропорциональной камерой, пригодной для использования при светимости менее $10^{32} \mathrm{Cm}^{-2} \mathrm{c}^{-1}$.

4. Использование созданных детекторов нового поколения непосредственно в экспериментах, а также детальные исследования их свойств свидетельствуют о ряде неоспоримых преимуществ этих детекторов со светосъемом оптоволоконной лентой по сравнению с известной, классической системой светосбора со световодом [3]. Среди этих преимуществ: компактность, способность функционировать в магнитных полях без дополнительной экранировки ФЭУ, существенно меньший темп деградации вследствие естественного старения [11].

5. Детальное изучение свойств нового сцинтилляционного материала UPS 923A и WLS волокон позволило предложить новую методику и получить ряд новых результатов [4]:

- физически мотивированный метод измерения объемной длины ослабления (BAL) сцинтиллятором собственного излучения и установление факта зависимости BAL от эффекта реабсорбции

- определение времени ( $\approx 2$ 2 $)$ нарастания импульса света в системе “UPS 923A + WLS”, что открывает возможность ее применения в быстрых системах совпадений и времяпролетных измерениях

- более чем двукратное превосходство созданного полистирольного сцинтиллятора UPS 923A по времени старения в сравнении с общеизвестным поливинилтолуольным сцинтиллятором NE 114 вследствие различий в химической структуре полимерных основ.

6. Создана экспериментально мотивированная основа прогнозирования старения сцинтилляционных счетчиков CDF II [15, 19]; установлено в частности, что техническая длина ослабления (TAL) комплекса "сцинтиллятор + оптоволокно" очень слабо меняется со временем и деградация на 80\% обусловлена старением пластика. Коллаборации дана программа замены теряющих эффективность счетчиков, эксплуатируемых с 1992 года. Вместе с этим установлено: счетчики ОИЯИ сохранят высокую эффективность до конца сеанса Run II. 
7. Предложен и экспериментально обоснован новый вариант триггера I уровня [18], дающий возможность регистрации мюонов в области $1.0<|\eta|<1.25$ в условиях существенно возросшей (до $2 \cdot 10^{32} \mathrm{~cm}^{-2} c^{-1}$ и выше) светимости Тэватрона. Показано, что размещение дополнительного слоя сцинтилляционных счётчиков в указанной области позволит коллаборации увеличить более чем на $10 \%$ количество отбираемых событий с мюонами в качестве сигнатурной частицы.

Основные результаты диссертации опубликованы в следующих работах:

\section{Статьи в научных журналах:}

1. Артиков А., Беллеттини Д., Будагов Ю. (коллаборация ОИЯИ-ИНФН). Подсистема счётчиков «miniskirt» установки CDF II // Письма в ЭЧАЯ. Дубна, 2002. - № 5 [114]. - С. 25-39.

2. Пухов О., Артиков А. (коллаборация ОИЯИ-ФНАЛ). Автоматизация контроля системы мюонных сцинтилляционных счётчиков CDF II // Письма в ЭЧАЯ. - Дубна, 2002. -№ 5[114]. - С. 72-81.

3. Artikov A., Budagov J. (JINR-INFN-Singl.Crist.Res.Inst. collaboration). Design and construction of new central and forward muon counters for the CDF II // Nuclear Instruments\&Methods. - Amsterdam, 2005. - A538. - P. 358-371.

4. Artikov A., Budagov J. (JINR-INFN collaboration). Properties of the Ukrainian polystyrene-based plastic scintillator UPS 923A // Nuclear Instruments \& Methods. - Amsterdam, 2005. - A555. - P. 125-131.

5. Abulencia A., ... Artikov A. (CDF collaboration) Top quark mass measurement using the template method in the lepton+jets channel at CDF II // Physical Review - Ridge/New-York, 2006. - D73: 032003. - P. 35.

6. Abulencia A., ... Artikov A. (CDF collaboration). Measurement of the top quark mass with the dynamical likelihood method using lepton plus jets events with b-tags in ppbar collisions at $\mathrm{s}^{1 / 2}=1,96 \mathrm{TeV} / /$ Physical Review Ridge/New-York, 2006. - D73: 092002. - P. 26.

7. Abulencia A., ... Artikov A. (CDF collaboration) Measurement of the top quark mass using template method on dilepton events in proton-antiproton collisions at $\mathrm{s}^{1 / 2}=1,96 \mathrm{TeV} / /$ Physical Review - Ridge/New-York, 2006. - D73: 112006. - P. 23.

8. Abulencia A., ... Artikov A. (CDF collaboration). Measurement of the $B_{s}^{0}=\bar{B}_{s}^{0}$ Oscillation Frequency // Physical Review Letters - Ridge/New-York, 2006. - 97: 062003. - P. 7.

9. Abulencia A., ... Artikov A. (CDF collaboration). Observation of $B_{S}^{0}-\bar{B}_{S}^{0}$ oscillations // Physical Review Letters - Ridge/New-York, 2006. - 97: 242003. - P. 8.

10.Abulencia A., ... Artikov A. (CDF collaboration). Measurement of the $t \bar{t}$ production cross-section in $p \bar{p}$ collisions at $\sqrt{s}=1.96$ TэB in the all-hadronic decay mode // Physical Review - Ridge/New-York, 2006. - D74: 072005. - P. 9 . 
11.Артиков А., Будагов Ю. (коллаборация ОИЯИ-ИНФН-Инст.Монокрист.). Большие мюонные сцинтилляционные счетчики нового поколения со съемом информации спектросмещающими волокнами для CDF II // Письма в ЭЧАЯ. - Дубна, 2006. - Т.3, № 3(132). - С.81-102.

12.Abulencia A., ... Artikov A. (CDF collaboration). Measurement of the $\Lambda_{b}^{0}$ lifetime in $\Lambda_{b}^{0} \rightarrow \mathrm{J} / \psi \Lambda^{0}$ in collisions at $\sqrt{s}=1.96 \mathrm{~T}$ ЭB // Physical Review Letters - Ridge/New-York, 2007. - 98: 122001. - P. 7.

13.Abulencia A., ... Artikov A. (CDF collaboration). Search for anomalous production of multi-lepton events in $p \bar{p}$ collision at $\sqrt{s}=1.96$ TэB // Physical Review Letters - Ridge/New-York, 2007. - 98: 131804. - P. 7.

14.Abulencia A., ... Artikov A. (CDF collaboration). Measurement of the helicity fractions of $\mathrm{W}$ bosons from top quark decays using fulli reconstructed $t \bar{t}$ events with CDF II // Physical Review - Ridge/New-York, 2007. - D75, 052001. - P. 11.

15.Artikov A., Chokheli D., Pukhov O., Pauletta G. On the aging of the scintillation counters for RUN II Muon System at CDF // Nuclear Instruments \& Methods. - Amsterdam, 2007. - A579. - P. 1122-1134.

16.Aaltonen T., ... Artikov A. (CDF collaboration). First Run II Measurement of the W Boson Mass // Physical Review - Ridge/New-York, 2008. - D77, 112001. - P. 48.

17.Артиков А., Пухов О., Члачидзе Г., Чохели Д. Система мюонных сцинтилляционных счетчиков установки CDF // Физика Элементарных Частиц и Атомного Ядра - Дубна, 2008. - Т.39, выпуск 3 - С. 788-811.

18.Артиков А., Члачидзе Г., Чохели Д., Бромберг К. О возможности модификации триггера 1 уровня мюонной системы установки CDF в условиях повышенной светимости Тэватрона // Письма в ЭЧАЯ. - Дубна, 2008. - Т.5, №2(144) - С. 171-188.

19.Артиков А., Пухов О., Чохели Д., Паулетта Дж. Об уменьшении со временем светосбора сцинтилляционных счётчиков мюонного триггера установки CDF // Письма в ЭЧАЯ. - Дубна, 2009. - Т.6, № 2(151). - С. 219-234.

\section{Препринты:}

20.Артиков А., Будагов Ю., Гринев Б., Данилов В., Лебедев В., Сенчишин В., Чохели Д. PRESHOWER - новый многоканальный детектор CDF. Сцинтилляционные пластины нового детектора: разработка, производство, контроль качества. // Препринт ОИЯИ. - Дубна, 2005. P13-2005-27. - C. 14.

21.Artikov A., Boudagov J. (JINR-FNAL collaboration). CDF central preshower and crack detector upgrade // FNAL, ANL and INFN preprints. - Batavia, Argonne and Pisa 2007. - Fermilab-PUB-07-023-E, ANL-HEP-PR-07-09, INFN-PI-N-2007-01. - P. 22. - e-Print: arXiv:0706.3922. Submitted to Nuclear Instruments \& Methods in 2008. 
Физика-математика фанлари доктори илмий даражасига талабгор Артиков Акрам Музафаровичнинг 01.04.16 - атом ядроси ва элементар заррачалар физикаси ихтисослиги бўйича "CDF II қурилмаси мюон комплекси ва электромагнит калориметр преконвертори оғир кварклар физикаси сохасидаги Тэватрон тажрибаларида" мавзусидаги диссертациясининг

\section{РЕЗЮМЕСИ}

Таянч сўзлар: $t$-кварк, $W$-бозон, $B_{s}^{0}-\bar{B}_{s}^{0}$ осцилляциялари, Хиггс бозони, CDF II қурилмаси, Тэватрон, интенсивлик, триггер, сцинтиллятор, детектор, мезон, назорат тизими, преконвертор, фотон, электрон, спектр силжитадиган (WLS) оптик толалар, нурланишни йиғиш, абсолют калибрлаш, минимал ионизацияловчи заррача, эскириш.

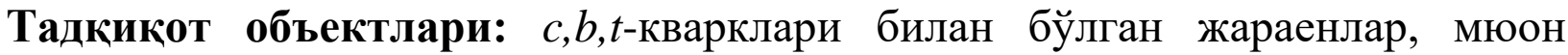
тизими ва триггери, электромагнит калориметри преконвертори, CDF II қурилмаси, пластик сцинтилляцион детекторлар.

Ишнинг мақсади: $t$-кварк ва $W$-бозон массаларини аниқ ўлчаш ва $B$ мезонлар парчаланишини муфассал ўрганиш каби актуал масалалардан иборат бўлган, оғир кварклар физикаси сохасидаги тажрибалар дастурини ижро этиш учун, CDF II қурилмаси детекторлар тизимини ишлаб чиқиш ва яратиш.

Тадкиқот услублари: спектрометрик канални абсолют калибрлаш услуби, энг аниқ хақиқатнамолик (DLM) услуби, «қолип» услуби, Боллингер ва Томасларнинг якка фотон услуби, эскириш коэффициентини аниқлаш услуби, хажмий кучсизлантириш узунлиги (BAL) ва техник кучсизлантириш узунлиги (TAL)ни аниқлаш услублари.

Олинган натижалар ва уларнинг янгилиги. $t$-кварк ва $W$-бозон массалари юқори даражали аниқлик билан ўлчанди, $B_{s}^{0}-\bar{B}_{s}^{0}$ осцилляциялари биринчи бор кузатилди ва уларнинг такрорланиш даражаси ўлчанди. Бу ва бошқа мухим ахамиятга эга бўлган физик натижаларга эришишни CDF II қурилмаси янги мюон системаси яратилиши ва тажрибада биринчи карра, нурланиши WLS оптик толалар ёрдамида йиғиладиган сцинтилляцион детекторларнинг мюон триггери таркибига киритилиши таъминлади. Бу хилдаги янги детекторлар хоссаларини тадқиқ қилиш жараенида янги услуб ишлаб чиқилди ва янги натижаларга эришилди: BALни аниқлаш учун сцинтилляцион нурланишни ўлчаш услуби биринчи бор таклиф этилди ва ишлатилди; «UPS 923A + WLS оптик толалари» детектори нурланиши импульсининг $\approx 2$ нс давомида ўсиши биринчи марта аниқланди; UPS 923A полистирол сцинтиллятори NE 114 поливинилтолуол сцинтилляторига нисбатан 2 баробар суст эскириши полимер структуралари орасидаги фарқи туфайли бўлади деб, биринчи карра хулоса қилинди. Сцинтиллятордан йиғиб олинган нурланишнинг вақт ўтиши билан камайишини систематик ўлчаш натижасида детекторнинг табиий эскиришини аниқлашга имкон берувчи оригинал усул таклиф этилди ва синалди. Бу усулни «UPS 923A + WLS оптик толалари» туридаги детекторлар учун қўллаш натижасида 
биринчи бор қуйидагилар аниқланди: оптик толалар хусусиятлари ёмонлашувининг детектор эскиришига кўшган хиссаси оз бўлиб, 20 \%ни ташкил этади; TALнинг вақт ўтиши билан ўзгариши ўта секинлик билан рўй беради.

Амалий ахамияти. $t$-кварк ва $W$-бозон массаларини аниқ ўлчаш, Хиггс бозон массасининг мавжуд бўлиш сохасиини чегаралайди, бу эса LHC (ЦЕРН) ва Тэватронлардаги бўлажак тажрибалар учун мухим ахамият касб этади. $B_{s}^{0}-\bar{B}_{s}^{0}$ осцилляцияларининг мавжудлиги, элементар зарачалар назарияси бўлмиш Стандарт Моделнинг илгари тадқиқ қилинмаган нозик ходисалар сохасида тўғрилигини исботлайди. Янги мюон тизими аксептансининг зериларли даражада, $60 \%$ га, ошиши ва электромагнит калориметрининг янги, илгаригисига нисбатан тезкорлиги ва $\eta$ бўйича сегментлиги 10 баробар оширилган преконвертори яратилиши, оғир кварклар физикаси сохасидаги тажрибалар дастурини ижро этишда CDF II курилмасининг имкониятларини жиддий даражада оширди. Детектор комплекслари яратилиши принципиал илмий ахамиятга эга бўлган янги мухим натижалар олинишини таъминлади, улар орасида $W$-бозон массасини ва «лептон + јеt» ва «дилептон» хилдаги парчаланишларда $t$-кварк массасини ўлчашлар ва бошқалар бор. Тэватрон ёруғлилиги ошганлиги $\left(\geq 2 \times 10^{32} \mathrm{~cm}^{-2} \mathrm{c}^{-1}\right)$ сабабли CDF II курилмасининг $1.0 \leq|\eta| \leq 1.25$ қисми учун таклиф этилган ва тажрибада синалган янги мюон триггери, аввалги триггер бекор қилиниши натижасида йўқотилган, таркибида мюон мавжуд бўлган 10 \% ходисаларнинг тажрибада хисобга олинишини таъминлайди.

Татбик этиш даражаси ва иқтисодий самарадорлиги фундаментал ва амалий характерга эга бўлиб, элементар заррачалар назариясини ривожлантиришда, ядро физикаси ва юқори энергияли заррачалар физикаси тажрибаларида сцинтилляцион детекторларни татбиқ этишда кўлланилиши мумкин.

Кўлланиш сохаси: юқори энергияли заррачалар физикаси, космик нурлар физикаси, экспериментал ядро физикаси, элементар заррачалар назарий физикаси, тезлатгич тажрибаларидаги курилмалар. 


\section{PЕЗЮМЕ}

диссертации Артикова Акрама Музафаровича на тему: "Мюонный комплекс и преконвертор электромагнитного калориметра установки CDF II в экспериментах по физике тяжелых кварков на Тэватроне" на соискание ученой степени доктора физико-математических наук по специальности 01.04.16 - физика атомного ядра и элементарных частиц.

Ключевые слова: $t$-кварк, $W$-бозон, $B_{s}^{0}-\bar{B}_{s}^{0}$ осцилляции, бозон Хиггса, установка CDF II, Тэватрон, светимость, триггер, сцинтиллятор, детектор, мюон, система контроля, преконвертор, фотон, электрон, спектросмещающие (WLS) оптические волокна, светосбор, абсолютная калибровка, минимально ионизирующая частица (МИЧ), старение.

Объекты исследования: процессы с $c, b, t$ - кварками, мюонная система и триггер, преконвертор электромагнитного калориметра, пластические сцинтилляционные детекторы установки CDF II.

Цель работы: Модернизация мюонного комплекса и преконвертора электромагнитного калориметра установки CDF II с целью выполнения высокоприоритетной программы экспериментов ОИЯИ-ФНАЛ по физике тяжелых кварков на Тэватроне, включающей прецизионные измерения масс $t$-кварка и $W$-бозона, детальное исследование распадов $B$-мезонов и др.

Методы исследования: метод абсолютной калибровки спектрометрического канала, (DLM) метод наибольшего правдоподобия, метод «шаблонов», однофотонный метод Боллингера и Томаса, метод определения коэффициента старения, методы определения объемной длины ослабления (BAL) и технической длины ослабления (TAL).

Полученные результаты и их новизна. С высокой точностью измерены массы $t$-кварка и $W$-бозона, впервые наблюдены $B_{s}^{0}-\bar{B}_{s}^{0}$ осцилляции и измерена их частота. Получение этих и многих других принципиально важных физических результатов обеспечено созданием новой мюонной системы установки CDF II с первым в практике экспериментов подобного рода включением в состав мюонного триггера сцинтилляционных детекторов со светосъемом WLS оптическими волокнами. Для исследования свойств детекторов подобного типа разработана новая методика и получены новые результаты: впервые предложен и отработан метод измерения собственного излучения сцинтиллятора для определения BAL; впервые определено время нарастания ( $\approx 2 \quad \mu c)$ импульса света в системе «UPS 923A + WLS оптоволокно»; впервые сделан вывод о различиях в структуре полимерных основ, являющихся причиной двукратного превосходства полистирольного сцинтиллятора UPS 923А по времени старения в сравнении с поливинилтолуольным сцинтиллятором NE 114. Предложена и апробирована оригинальная методика определения естественного старения сцинтилляционных детекторов путем регулярного измерения уменьшения светосбора со временем. С применением этой методики для счетчиков типа «UPS 923A + WLS оптоволокно» впервые определены: а) вклад оптоволокна 
в старение детектора; он невелик, $\approx 20 \%$ и б) слабая зависимость изменения TAL от времени.

Практическая значимость работы. Прецизионные измерения масс $t$-кварка и $W$-бозона ограничивают область возможных масс Хиггс бозона, что чрезвычайно важно для предстоящих экспериментов на LHC (ЦЕРН) и Тэватроне, а обнаружение $B_{s}^{0}-\bar{B}_{s}^{0}$ осцилляций подтверждает правильность Стандартной Модели в ранее не исследовавшейся области тонких явлений. Значительное, на $60 \%$, увеличение аксептанса новой мюонной системы и создание нового преконвертора электромагнитного калориметра, на порядок превосходящего предыдущий детектор по быстродействию и гранулярности по псевдобыстроте, несомненно преумножили возможности модернизированной установки CDF II в исполнении запланированной программы экспериментов по физике тяжелых кварков. Созданные детекторные комплексы обеспечили достижение важных новых результатов принципиального научного значения, среди которых прецизионное измерение масс $t$-кварка в топологиях «лептон + струи» и «дилептон» и $W$ бозона и многое другое. Предложенный и экспериментально апробированный новый мюонный триггер в области $1.0<|\eta|<1.25$ для использования в условиях возросшей $\left(\geq 2 \times 10^{32} \mathrm{~cm}^{-2} \mathrm{c}^{-1}\right)$ светимости Тэватрона обеспечивает возвращение $10 \%$ «мюонных» событий, потерянных вследствие отмены предыдущего триггера

Степень внедрения и экономическая эффективность. Работа носит фундаментальный и прикладной характер; ее результаты могут быть использованы в развитии теории физики элементарных частиц и практике применения сцинтилляционных детекторов в экспериментах по ядерной физике и физике высоких энергий.

Область применения: физика высоких энергий, физика космических лучей, экспериментальная ядерная физика, теория элементарных частиц, установки для экспериментов на ускорителях и коллайдерах. 


\section{RESUME}

\section{Thesis of Akram Muzafarovich Artikov}

of the scientific degree competition of the doctor of sciences

in physical and mathematical sciences speciality 01.04.16 - physics of atom

nuclei and elementary particle subject

"Muon complex and preshower of electromagnetic calorimeter of the CDF II setup on the Tevatron heavy quark physics experiments"

Key words: $t$-quark, $W$-boson, $B_{s}^{0}-\bar{B}_{s}^{0}$ oscillations, Higgs boson, spectrometer setup CDF II, Tevatron, luminosity, trigger, scintillator, detector, muon, control system, preshower, photon, electron, wavelength shifting (WLS) optical fiber, light collection, absolute calibration, minimum ionizing particle (MIP), aging.

Objects of investigation: processes with $c, b, t$-quarks, muon system and trigger, preshower of the electromagnetic calorimeter, plastic scintillation detectors of the CDF II setup.

Goal of work: development and construction of the detector systems of the CDF II setup for executing the experimental research program in heavy quark physics including precision measurements of the $t$-quark mass and $W$-boson mass; detailed study of $B$-mesons decays etc.

Methods of the research: the method for absolute calibration of the spectrometric channel, dynamical likelihood method (DLM), "template" method, BollingerThomas single photon method, the method of aging coefficient determination, bulk attenuation length (BAL) and technical attenuation length (TAL) determination methods.

Results obtained and their novelty. The $t$-quark and $W$-boson masses are measured with a high precision; for the first time the $B_{s}^{0}-\bar{B}_{s}^{0}$ oscillations are detected and their frequency is measured. These results and many other physics data of principal importance are reached due to the new muon system of the CDF II setup, which included (for the first time in this sort of experiments) scintillator counters with the WLS optical fibers. To investigate properties of such detectors, a specific method to measure the inherent irradiation of the scintillation detectors for determining the BAL was proposed for the first time and optimized; the light pulse rise time $(\approx 2 n s)$ in the "UPS 923A + WLS optical fibers" system was determined for the first time; a conclusion was made for the first time on a polymer base structures difference as a reason of a twofold superiority of the polystyrene scintillator UPS 923A in aging time over that of the polyvyniltoluene scintillator NE 114. A unique novel method for determining natural aging of scintillation detectors by systematic measurements of the light collection time decrease was proposed and approved experimentally. Used with the "UPS 923A + WLS optical fibers" detector, this method made it possible for the first time to determine a moderate (20\%) optical fiber contribution to the detector aging and weak of TAL change with time.

Practical significance of the work. The precision top-quark and $W$-boson mass measurements limit the possible mass range of the Higgs boson, which is of 
extreme importance for the forthcoming LHC (CERN) experiments and current Tevatron studies; the observation of $B_{s}^{0}-\bar{B}_{s}^{0}$ oscillations confirms validity of the Standard Model in the earlier uninvestigated field of a thin effects. Significant (by $60 \%$ increase of a new muon system acceptance and creation of a new electromagnetic calorimeter preshower surpassing the previous ones by an order of magnitude both in operation speed and in rapidity granularity, undoubtedly increased the possibilities of the modernized CDF II setup in the execution of the planned experimental program for heavy quarks studies. The created detector complexes have allowed reaching of an important new physics results of principal scientific significance, among which are the precision measurements of the $t$-quark mass (in "lepton + jet" and "dilepton" topology) and $W$-boson mass and many others. The proposed and experimentally tested new muon trigger in the $1.0 \leq|\eta|$ $\leq 1.25$ interval to be used under increased $\left(\geq 10^{32} \mathrm{sm}^{-2} \mathrm{~s}^{-1}\right)$ Tevatron luminosity, provides "return" of $10 \%$ of muon events lost due the cancellation of the previous trigger.

Degree of introduction and economic efficiency. The work is of fundamental and applied nature: its results can be helpful for development the elementary particles theory and the use of scintillation detectors in nuclear physics and high energy physics experiments.

Sphere of application: high energy physics, cosmic-rays physics, theory of elementary particles, research setups for accelerator and collider experiments. 